\title{
SWAP 4 - Technical addendum to the SWAP documentation
}

Marius Heinen, Martin Mulder, Joop Kroes

Wageningen Environmental Research

January, 2021

$\underline{\text { https://doi.org/10.18174/540451 }}$

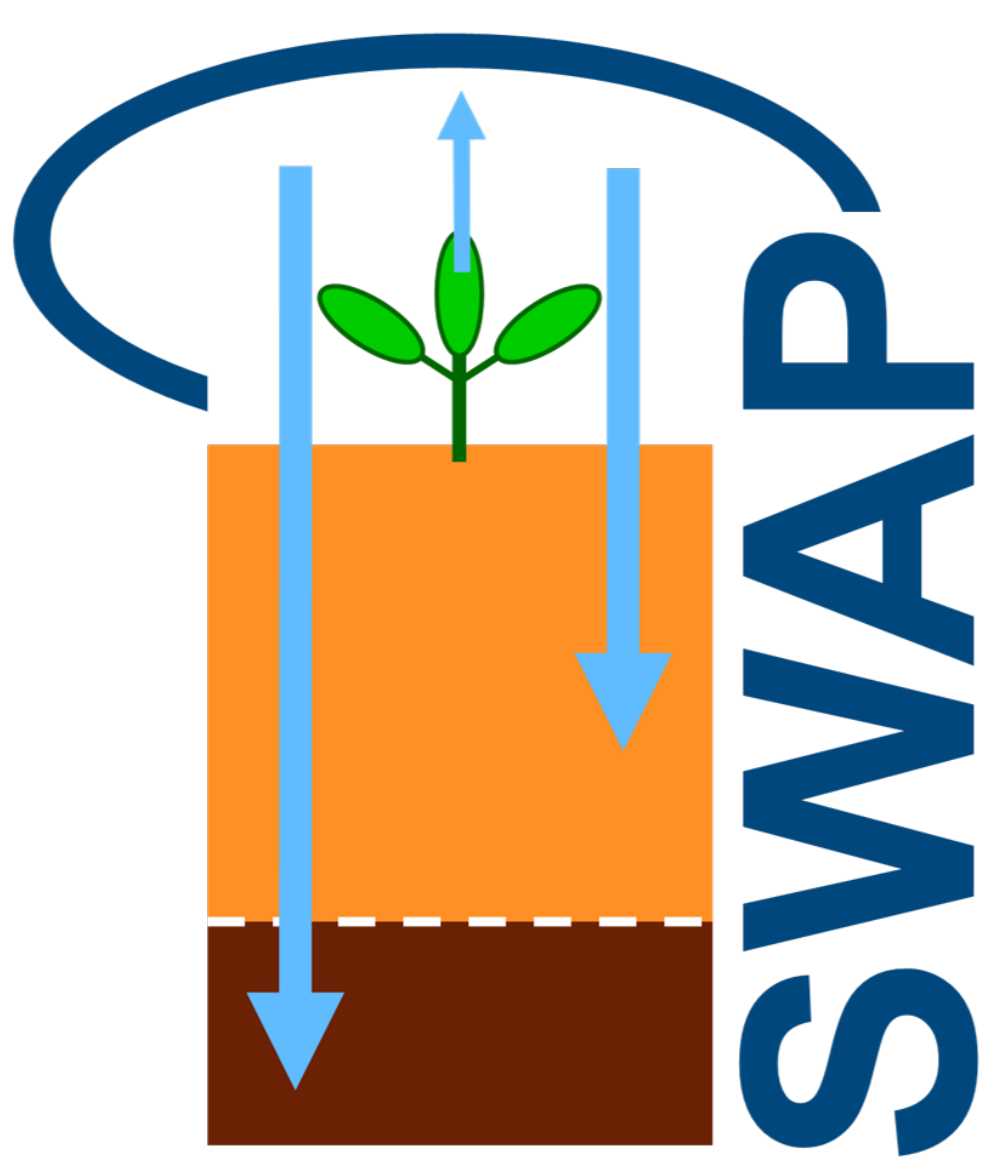




\section{Contents}

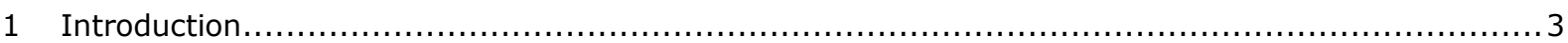

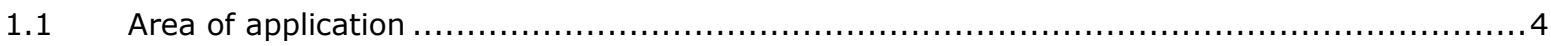

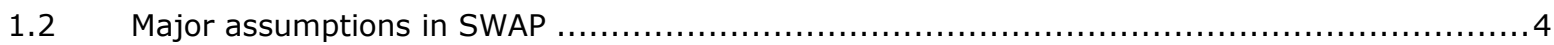

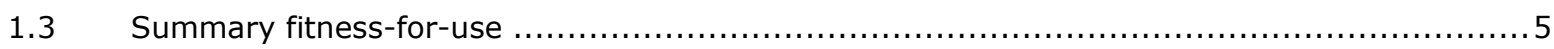

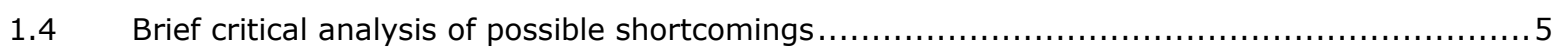

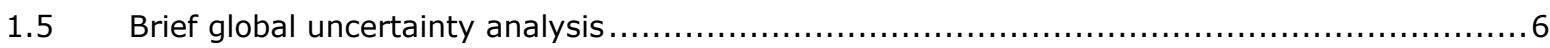

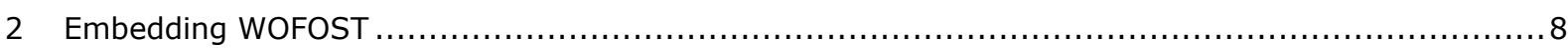

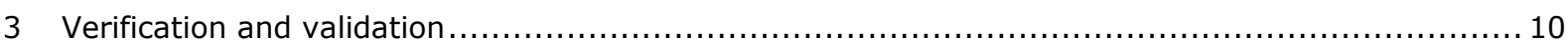

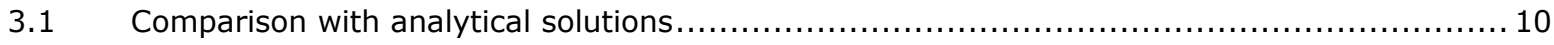

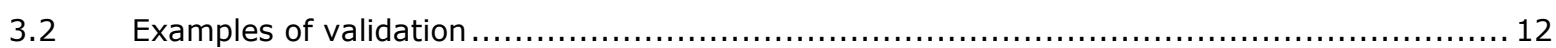

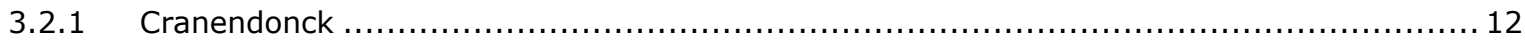

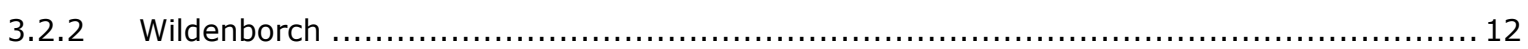

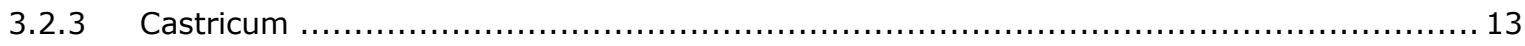

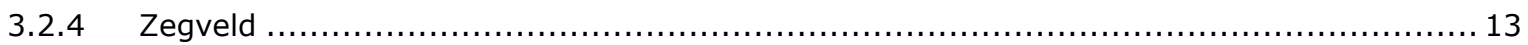

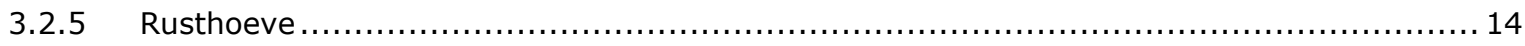

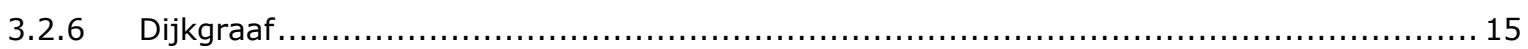

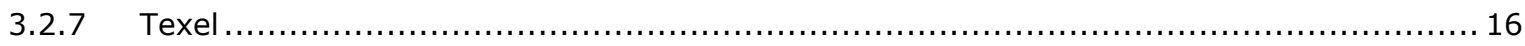

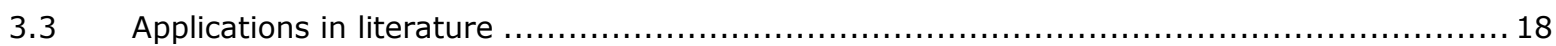

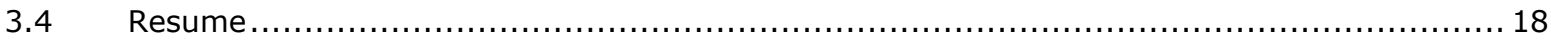

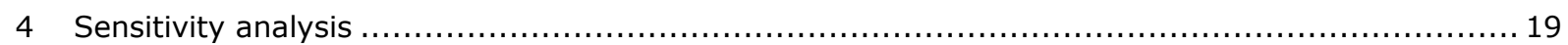

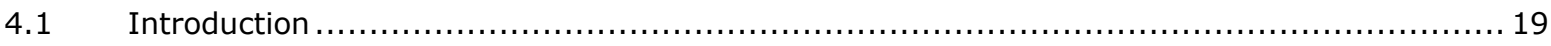

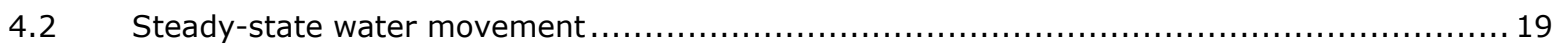

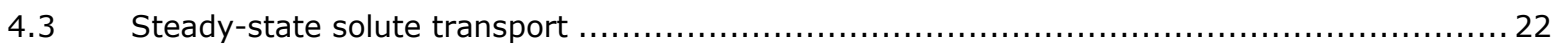

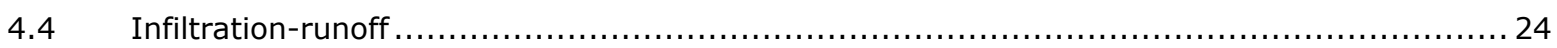

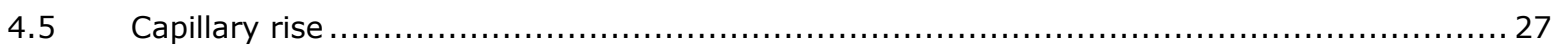

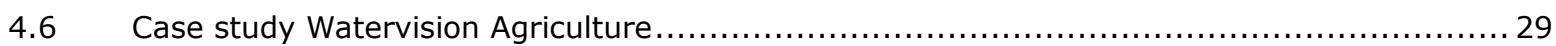

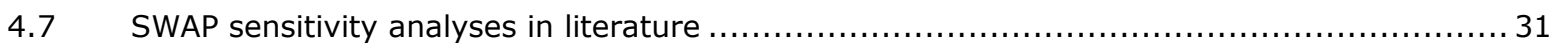

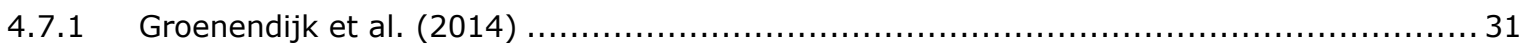

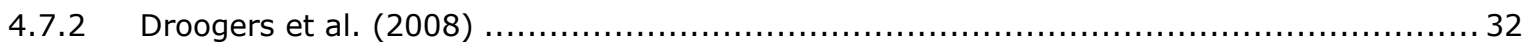

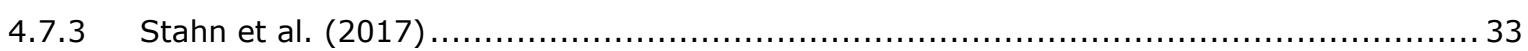

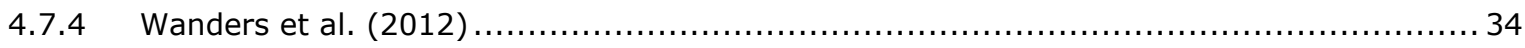

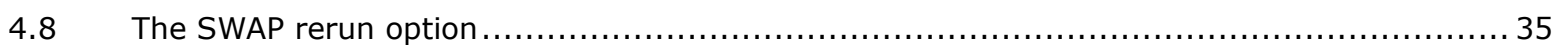

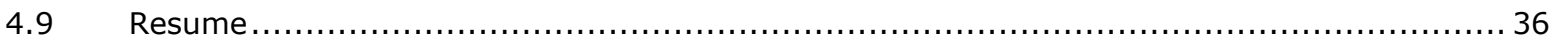

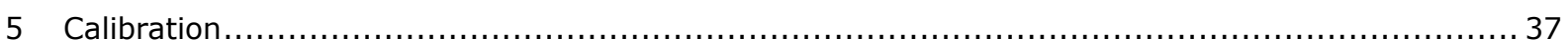

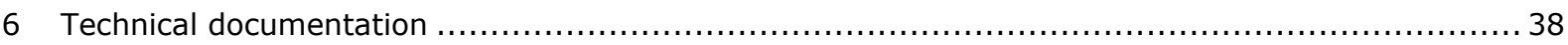

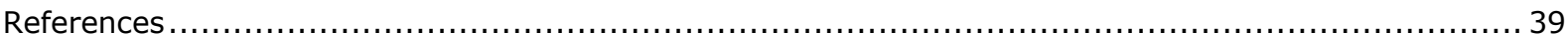




\section{Introduction}

SWAP deals with soil water movement and soil water balance in the upper part of the soil consisting of the unsaturated (vadose) zone and the upper part of the saturated (groundwater) zone (see cover picture of the SWAP manual, and Figure 1.1 of the SWAP manual) (Kroes et al., 2017). Although the principal direction of soil water movement in the unsaturated zone is often vertical (upward, downward), due to interaction with groundwater and drains (drain tubes, ditches, canals) in practice soil water movement should be considered as a three-dimensional process. However, full 3D simulation of soil water movement would result in a complex simulation model with complex and detailed boundary conditions. Therefore, it was decided to set up SWAP as a 1D simulation model, in which interaction with the surroundings is modelled as additional sinks (drains) and sources (infiltration from ditches, drains). This makes then SWAP as a quasi-3D model.

Another major component in the water balance is the interaction with the atmosphere and crop. SWAP uses the atmospheric conditions as upper boundary condition (rainfall, demand for evapotranspiration). The crop is explicitly simulated in SWAP via incorporation of the WOFOST model for major arable crops (maize, potato, sugar beet, winter wheat, (summer) barley). For grassland a detailed crop growth module was derived according to the same philosophy as WOFOST. Other crops can be simulated via a simple crop growth module.

SWAP consists of clearly defined modules for soil water flow, soil heat flow, solute transport, crop growth, macropore flow and interaction with groundwater and surface water systems. Figure 1 provides the sequential flow chart along all components during a simulation.

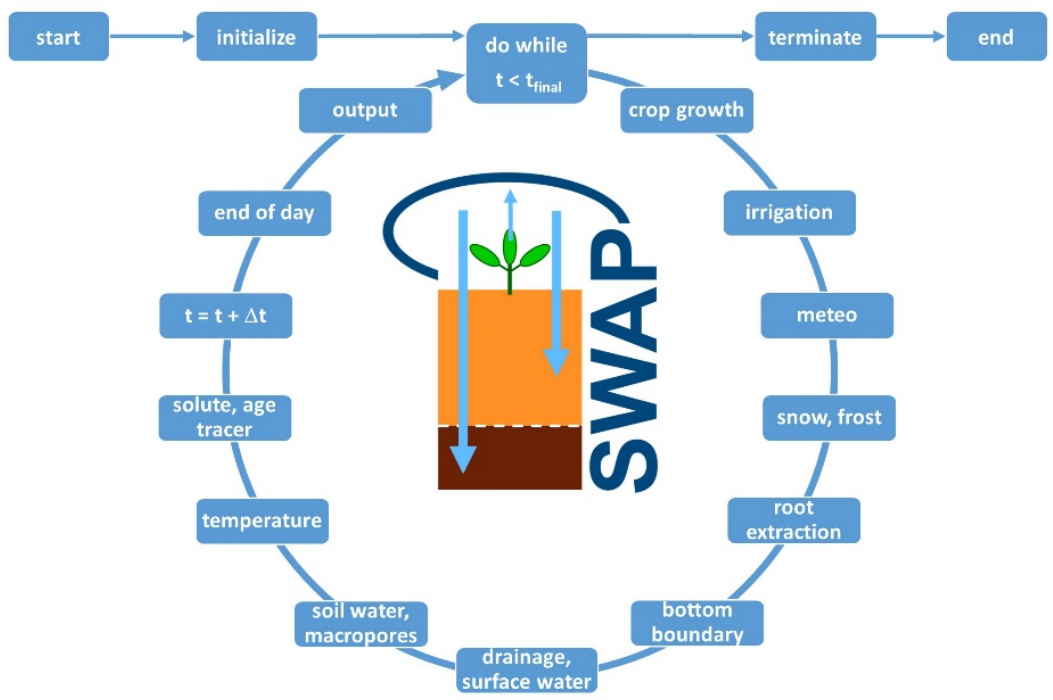

Figure 1. Schematic representation of the flow diagram in SWAP including the circular sequence of modules (if active) that are considered during each simulation times step.

The SWAP manual starts with a detailed description of the theory of soil water movement in soils (Chapter 2) followed by a detailed description of the top boundary conditions (evapotranspiration, rainfall; Chapter 3). Other chapters include specific details such as the quasi-3D elements due to surface runoff, an interception with drains (Chapter 4) or surface water (Chapter 5). Other chapter refer to specific aspects like macropore flow (Chapter 6), crop growth (WOFOST, grass, simple; Chapter 7), 
solute transport (Chapter 8), soil heat flow (Chapter 9), snow and frost handling (Chapter 10) and irrigation (Chapter 11).

\subsection{Area of application}

The core of SWAP is formed by the general water movement equation in porous media (soil). This is a non-linear, partial differential equation. It has to be solved by numerical mathematics, and the solution is determined by the initial and boundary conditions of the system considered. Technically the implementation of the numerical solution procedure in SWAP has been verified via comparison with analytical solutions (see Section 3): from the good correspondence it can be concluded that the core of SWAP is well programmed. Applications of SWAP in practice are fully determined by the user-supplied initial condition and boundary conditions. This is part of the modelling that depends on the user, for which SWAP offers several options and sub-models. The result of the SWAP simulation is highly dependent on the user-supplied information (remember: garbage in = garbage out).

SWAP is primarily meant for simulating one-dimensional situations (vertical water movement), with possibilities of exchange of water with the surroundings via drainage and/or infiltration to/from drainage systems (drain tubes, ditches, canals); SWAP can thus be seen as quasi-three-dimensional. SWAP results should be seen as outcome for the square-meter scale up to the scale of a single field or parcel. For larger areas several SWAP runs need to be performed. Horizontal exchange of water between individual SWAP soil columns is not automatically possible.

For detailed 2D or 3D calculation SWAP cannot be used; for example, the determination of the extent of the wetted bulb underneath a dripper cannot be simulated.

\subsection{Major assumptions in SWAP}

SWAP is based on the following major assumptions:

- $\quad$ water movement is dominantly one-dimensional (vertical); quasi-three-dimensional aspect have been included as exchange with drainage systems (drain tubes, ditches, canals; infiltration from these systems into the soil can also be considered);

- water movement in porous media requires that the porous medium (soil) is rigid, isotropic, isothermal and water is incompressible; swelling and shrinking can be partly considered in case the option macropore flow is used;

- $\quad$ only single phase flow (water) is considered; air in the soil always remains at atmospheric pressure;

- $\quad$ soils can be variably saturated;

- $\quad$ soils can be heterogeneous: the soil then consists of different soil layers each with its own soil physical properties; in principal these are given by the Mualem - van Genuchten equations (other relationships could be provided as tabulated input data); hysteresis can be considered when the Mualem-van Genuchten relationships are used;

- top and bottom boundary conditions can be either flux-controlled or pressure head controlled; at the bottom boundary several options can be considered; at the top a pressure head condition cannot be supplied by user but only occurs internally when ponding arises;

- transpiration reduction can be caused due to drought, lack of oxygen (too wet) or too saline conditions; transpiration reduction is used in WOFOST to predict crop growth reduction;

- $\quad$ ponding at the soil surface occurs when the infiltration capacity is exceed; surface runoff occurs after a threshold ponding height is exceeded and is calculated in analogy to Manning's overland flow;

- $\quad$ multiple level drainage systems can be considered to mimic discharge in a sub-catchment; imposed water levels in these drainage systems can be considered;

- macropore flow can be considered as a special case (e.g. for structured soils such as clay and peat); shrinkage and swelling of these macropores can be included;

- the crop is explicitly simulated in SWAP via incorporation of the WOFOST model for major arable crops (maize, potato, sugar beet, winter wheat, (summer) barley); for grassland a detailed crop 
growth module was derived according to the same philosophy as WOFOST; other crops can be simulated via a simple crop growth module;

- $\quad$ solute transport is described by the dispersion-diffusion - convection equation including simple transformation equations, adsorption and root uptake; for more detailed solute transport coupling of SWAP with ANIMO (Groenendijk et al., 2005; Renaud et al., 2005) is suggested; a simple single-layer $\mathrm{N}$-module is present (Groenedijk et al., 2017);

- $\quad$ soil temperature can be simulated as a diffusion process; soil temperatures can influence crop growth, solute transformations etc.;

- $\quad$ simple snow and frost options are available (requires soil temperature);

- $\quad$ irrigation can be considered either as fixed times and quantities, or chosen from five trigger options and three irrigation depth (amount) criteria.

\subsection{Summary fitness-for-use}

SWAP can be downloaded from the website (swap.wur.nl) and comes as a zip-file. This file can be unzipped to any folder. No formal installation procedure is required (no administration right is needed). Standard, SWAP is available as an executable for Windows platforms. The source code is available, so that users are able to produce their own executables e.g. for Linux platforms; from own tests we know that SWAP can be compiled and run under Linux without changes in the source code.

SWAP is not a simple, graphically oriented plug-and-play application. The user must supply information in ASCII input files and then run SWAP by hand indicating the name of the main input file (.swp); see general description section 1.4 of the manual. After completion of the model run, the results are available in several output ASCII files. The user can use these in their own scripts for further analyses.

Basically, based on meteorological information, crop parameters, soil properties, initial and boundary conditions SWAP predicts as a function of time the different water balance components in this system. It is the user that supplies all the necessary information, which will be used by the in SWAP implemented theories to predict the fate of water. Output is available as a function of time which can be further analysed by the user.

SWAP is also used in Wageningen University courses. For this a specific graphical user interface was developed so that students can easily change major input information and visualize major output information. Since not all functionalities of SWAP have been incorporated in this GUI, this interface is not distributed together with SWAP download.

\subsection{Brief critical analysis of possible shortcomings}

The SWAP model is basically a calculator that solves a partial differential equation based upon input information (initial and boundary conditions) as supplied by the user. Technically, the core of the model has been verified against analytical solutions (see Chapter 3). This means that the quality of the output for a user-defined situation is then mainly determined by the quality of the input as supplied by the user (garbage in = garbage out). This is something that cannot be controlled or checked by the model code. The only check performed by the model is done by checking the input values against pre-defined ranges in the source code.

SWAP is basically a point-model in space and only considers depth along which variable soil conditions can be considered. Real soils are heterogeneous, soil water movement may sometimes be 2- or 3dimensional (e.g., underneath drip irrigation), and soils and their properties may change in time (e.g., swelling-shrinking; compaction). These aspects cannot be considered in a single SWAP run.

See further the description provided on major assumption (Section 1.2) and fitness-for-use (Section 1.3). 


\subsection{Brief global uncertainty analysis}

As mentioned above, SWAP is basically a simulation model for one-dimensional problems (a point model in terms of surface area). By adding the possibilities of side boundary conditions mimicking possible exchange with the surrounding via different levels of drainage/infiltration boundaries, the SWAP application can thus be extended to a field or parcel. However, the outcome still refers to a vertical distribution of state variables. As such, it cannot predict horizontal variation within the field. Comparison with measured field data (e.g. groundwater level, water content, crop yield) can show a mismatch since, for example, the groundwater level gauge may have been installed at a position that is not comparable with the (average) information that was used as input in the model. This means that uncertainty in model outcome is likely present.

Below a brief and global description regarding uncertainty is provided. For future status-A qualification it may be required to perform a more in-depth qualitative uncertainty analysis. For that we could follow the suggested approach by Janssen et al. (2003) and Walker et al. (2003) (see for example how this was done in Pouwels et al., 2018). Such an analysis should focus on the following aspects: context, model, inputs, parameters, output (cf. Walker et al., 2003).

\section{Context}

SWAP is used on a diversity of projects and research questions with focus on the water balance in the unsaturated-saturated top part (down to one to a few meters) of soils, often in relation to agricultural crop production. Often, these involve studies where geographic differences need to be studied. For that relevant information needed as input should be available at the scale of interest. In order to simulate a region this means that several stand-alone SWAP simulations are needed which are representative for a small area of the total region of interest. The geographical variability in the outcome is then purely driven by the input information. SWAP is a pure technical model and does not include economics, social and political aspects.

\section{Model}

Technically, the numerical solution for water movement, solute transport and soil temperature has been verified against analytical solutions, and validation against field data has been performed (see Chapter 3). This, however, does not guarantee certainty in overall SWAP model outcome.

Over the decades the structure of the model has evolved and likely there is a good logistics in exchange of information between the different modules and the sequence in which these modules are used (see Figure 1). Several modules are present in SWAP but not all are as sophisticated as others.

In scientific community different descriptions exist for different processes, indicating that there is no universal description available. In SWAP some processes have different alternatives that can be used, either i) depending on data availability or ii) on desired details for which a subprocess needs to be considered. As an example for i): for crop growth it is advised to use the WOFOST module for those types of crops for which default WOFOST data files are available; when other crops need to be considered SWAP offers a simplified crop growth module. As an example for ii): root water uptake is often modelled via the so-called Feddes reduction model in SWAP, but alternative root water uptake models are available that take into account the root-soil interface. One such detailed root water uptake model is already implemented in SWAP and another one will be implemented soon.

There is an option to include snow and frost in SWAP. This is done in a simple way, as these processes hardly play a role for (current) Dutch conditions. A detailed macropore option is present in SWAP. It is not used often, since it requires many input parameters for which data are lacking. Soil temperature can be simulated, and is required in case solute transport or the $\mathrm{N}$-module is considered. Soil temperature is dependent on soil volumetric water content, but heat transport via moving water is not included. 


\section{Inputs}

The outcome of a SWAP simulation is highly driven by the quality of the input information. In the Netherlands, modellers (users) likely will make use of information obtained from the Dutch soil map, the Staring series (Heinen et al, 2020) or the derived soil physical units map (BOFEK2020, which is derived from the soil map and the Staring series; Heinen et al., 2021a). Some crop parameters can be obtained from the standard WOFOST database, but for other crops this information must be obtained via expert judgement.

\section{Parameters}

In SWAP most of the information needed to perform the simulation is based on information provided by the user (via text input files). In some cases universal or literature constants (parameters) have been hard coded (mostly as parameters in the top of the routine/function/module). For official releases the source code is available and then these parameters might be changed if needed. In the future we might consider to have all hard coded parameters listed in a special parameter input file. This, however, only provides more flexibility, and will not automatically lead to more certain outcome.

\section{Model outcomes}

Many outcome variables are available, and users are able to indicate what information they want as output. The output itself comes as is, i.e., no qualitative or quantitative information on the reliability or uncertainty of the outcome is given.

All-in-all, SWAP-WOFOST fulfils in the need of having a simulation tool that can consider the water balance in the combined soil-crop domain. It makes use of universally accepted process descriptions, and it is widely used both nationally and internationally, indicating that it is an accepted tool for this type of research problems. Despite this acceptance as well as some shortcomings in the model, we are aware that the modelling outcome comes with uncertainties. Such shortcomings are less likely the result of errors in the numerical implementation (solution) of the governing differential equations, and are more due to uncertainties in the available input information. Therefore, it is strongly advised that for each new study (application) the user should perform some kind of sensitivity analysis to determine where possible problems or uncertainties in outcome may arise. 


\section{Embedding WOFOST}

WOFOST (World Food Studies; Boogaard et al., 2014) is a stand-alone model to predict potential and water-limited crop production (available at: https://www.wur.nl/en/Research-Results/ResearchInstitutes/Environmental-Research/Facilities-Products/Software-and-models/WOFOST.htm). The Fortran version of WOFOST 7.1 is embedded in the SWAP Fortran code, where specific changes were implemented needed for the two-way interaction between SWAP and WOFOST. For example, the internal water balance in WOFOST is no longer used as the transpiration reduction is now calculated by SWAP and transferred to WOFOST where it may result in reduced crop growth. Vice versa, the leaf are index calculated by WOFOST is exchanged with SWAP where it is used to divide evapotranspiration in transpiration and evaporation.

WOFOST is one of the well-known Wageningen crop growth models by the school of C.T. de Wit. All these Wageningen models follow the hierarchical distinction between potential and limited production, and share similar crop growth sub models, with light interception and $\mathrm{CO}_{2}$ assimilation as growth driving processes, and crop phenological development as growth controlling process.

The major developments in WOFOST will be monitored. The development team of WOFOST has decided to change from the Fortran language to Python, so that the maintenance of the Fortran code is likely no longer guaranteed. Since WOFOST is based on generally accepted crop growth modelling theories by the school of C.T. de Wit, it is not likely that major changes in performance of WOFOST can be expected.

In order to verify that the implementation of WOFOST embedded in the SWAP Fortran code can reproduce the results of the standalone WOFOST version a set of pre-defined test cases are used (de Wit et al., 2019; https://github.com/ajwdewit/pcse/tree/master/tests/test data). The reference set has been generated for 11 locations across Europe and covers 7 different crops which leads to 44 unique test cases since not all crops are cultivated on all locations. Only the potential crop growth is considered since the water-limited crop growth is depending on hydrological soil moisture conditions calculated by SWAP.

Figure 2 shows the mean absolute error in the simulated development stage, leaf area index and aboveground biomass. Situation a) refers to first test (SWAP_4.1.68). After minor changes in the SWAPWOFOST code successive improvements were obtained (situations b) SWAP_4.1.68a and c)

SWAP_4.1.69). 
a)

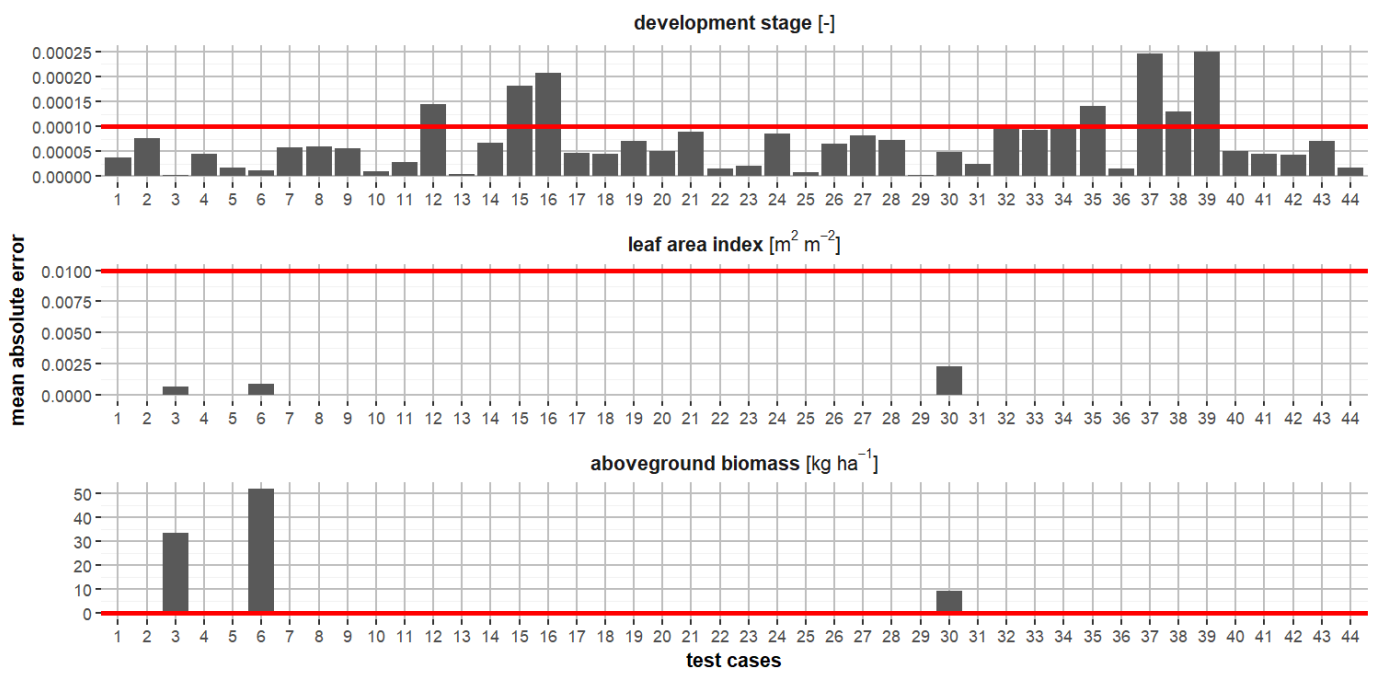

b)

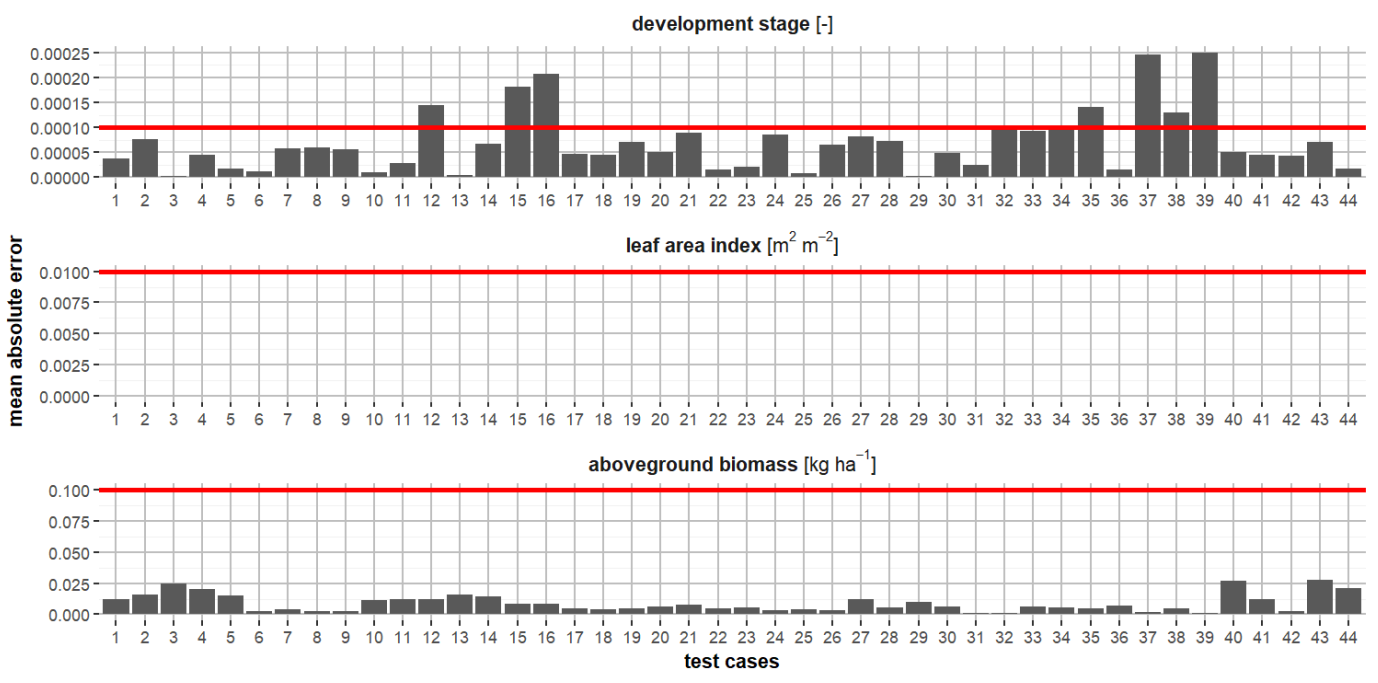

c)
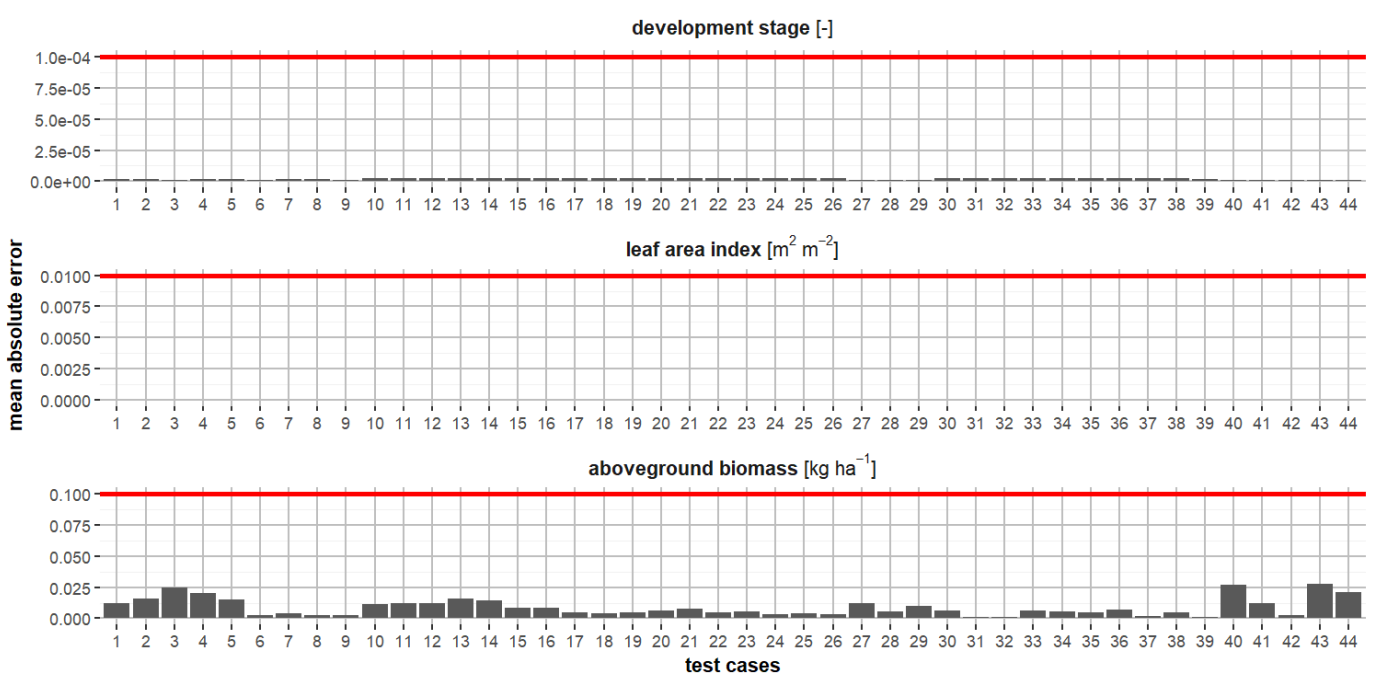

Figure 2. Mean absolute error simulated outputs of development stage, leaf area index and aboveground biomass by SWAP-WOFOST. Note the changes in y-axes. 


\section{Verification and validation}

\subsection{Comparison with analytical solutions}

The core of SWAP is the numerical solution of the non-linear partial differential equation (the so-called Richards equation) describing water movement in porous media. In order to verify whether or not the numerical solution in SWAP is correctly implemented it is useful to compare SWAP simulations with analytical solutions. However, since the Richards equation is a non-linear partial differential equation, analytical solutions are scarce, and often require specific constitutive relationships. By default SWAP uses the Mualem (1976) - van Genuchten (1980) constitutive relationship escribing the non-linear relations between volumetric water content, pressure head and hydraulic conductivity. For these situations no analytical solution are known. Analytical solutions can be produced in case these relationships are of exponential form. In the following we compare analytical transient infiltration profiles from the literature in which the water retention characteristic is given by

$$
S=\frac{\theta-\theta_{r}}{\theta_{s}-\theta_{r}}=\exp (\alpha h)
$$

and the hydraulic conductivity function is given by

$$
K=\exp (\alpha h)
$$

The differential moisture capacity $C=\mathrm{d} \theta / \mathrm{d} h$ is also needed in SWAP and follows easily from Eq. (1): $\alpha\left(\theta_{s}-\theta_{r}\right) \exp (\alpha h)$. For this purpose the SWAP code was temporarily adapted such that the Mualem- van Genuchten calculated $\theta, K$ and $C$ were overruled by these exponential relations [in SWAP source code functions watcon, hconduc, moiscap]. Best results were obtained when the SWAP option to include $K$ implicitly in the solution procedure was used. For this purpose also the derivative $\mathrm{d} K / \mathrm{d} h$ needs to be known, which follows from Eq. (2) as $\alpha \exp (\alpha h)$ [in SWAP source code functions dhconduc].

The first example is from Basha (1999) where infiltration in a uniform dry soil can be calculated up to the time of ponding. The parameter settings of Basha (199) were slightly adapted such that the time of ponding (also available as an analytical solution) occurred exactly at $150 \mathrm{~min}$. Figure 3 shows the excellent comparison between SWAP simulations and the analytical solution. 


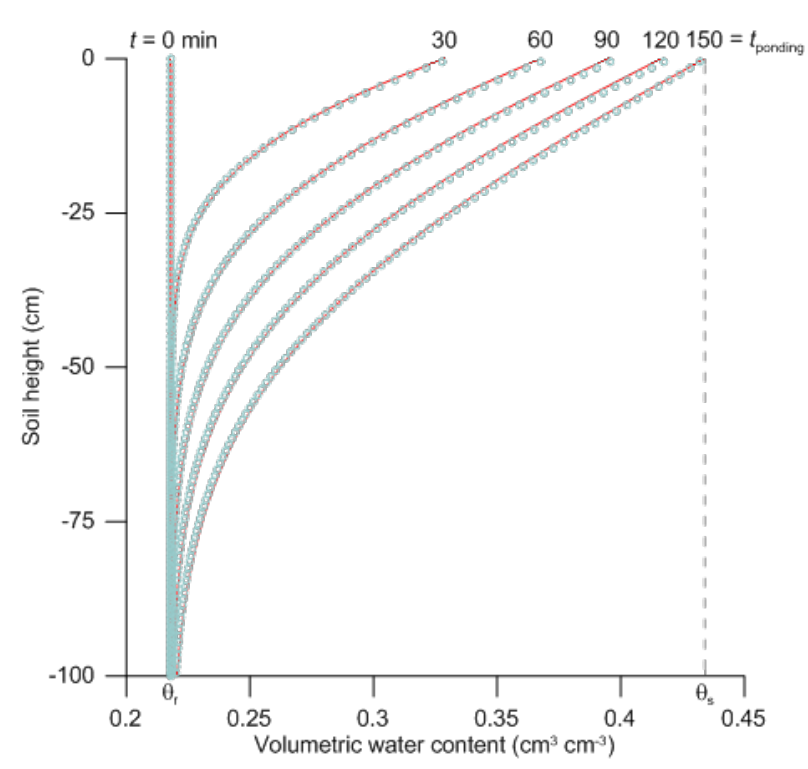

Figure 3. Volumetric water content as a function of soil depth for different times after start of constant rainfall up to the time of ponding according to the analytical solution of Basha (1999; red lines) and SWAP (symbols).

The second example refers to infiltration into a layered soil as provided by Srivastava and Yeh (1991), using their parameter settings. Also here the SWAP simulations for $h(z)$ (Figure 4a) and the outflow rate at the bottom of the soil column (Figure $4 \mathrm{~b}$ ) are equal to the analytical solutions.

a

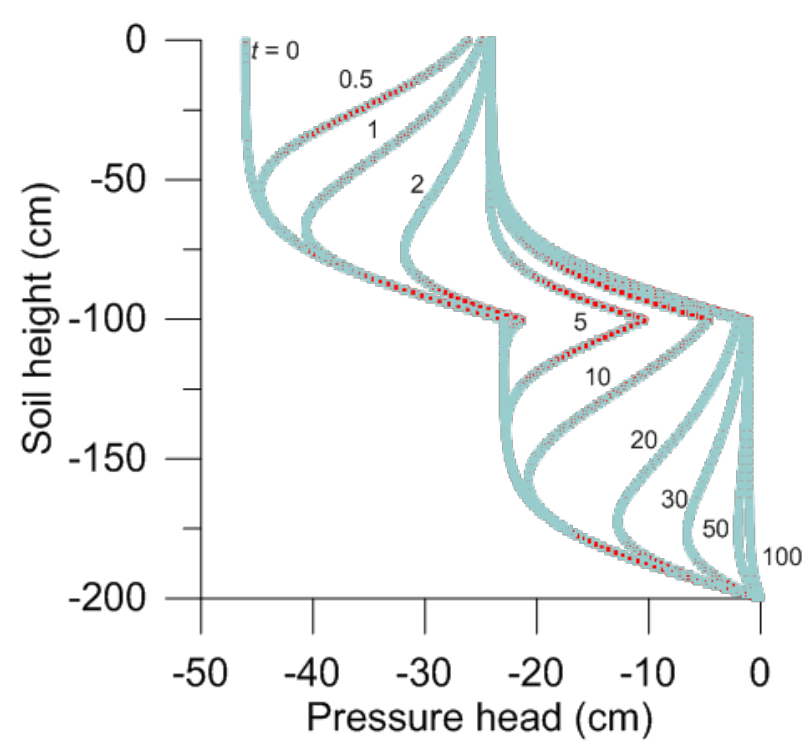

b

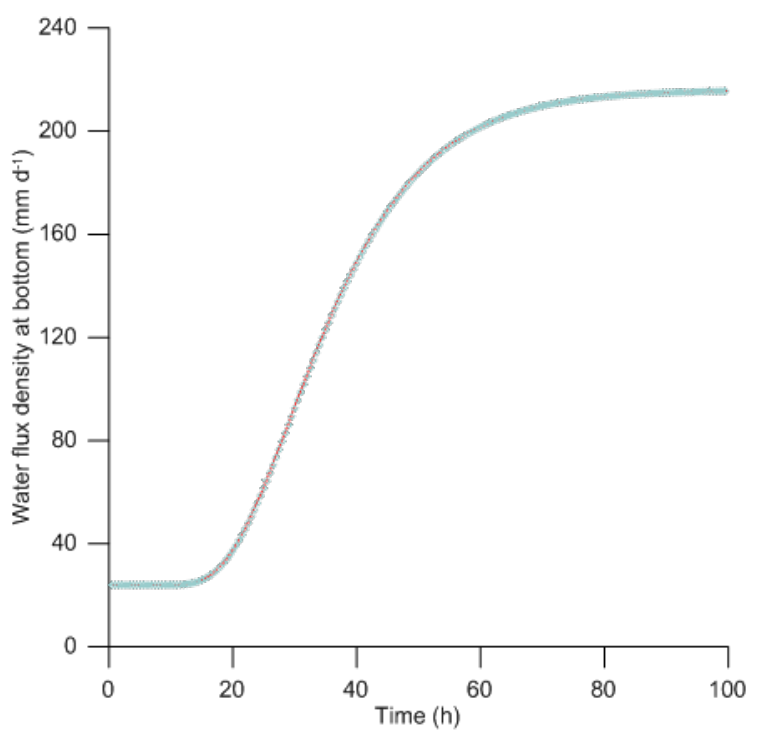

Figure 4. a) Pressure head as a function of soil depth for different times (h) after start of constant rainfall in a layered soil according to the analytical solution of Srivastava and Yeh (1991; red lines) and SWAP (symbols), and b) the corresponding simulated and analytical water flux outflow at the bottom of the soil profile considered. 
These two examples verify that the numerical solution of the partial differential equation with a flux-type boundary condition at the top is correct.

\subsection{Examples of validation}

Some say a simulation model is never validated enough or is never completely validated. This is typically the case for models that deal with a great diversity of aspects (processes) and parameters, like in SWAP. Furthermore, comparison of model predictions with field data is not always possible in an objective way, since it is unlikely that field experiments are performed such that all required model input data are known/measured.

The current standard set of test cases against which each new SWAP release is tested contains a few cases where field data are available for comparison with simulated data. These will be briefly illustrated below.

\subsubsection{Cranendonck}

Growth of forage maize on sandy soil, well fertilized with N (no official reference; Joop Kroes, pers. comm.). For maize we used the standard WOFOST crop file for maize. The soil consisted of $60 \mathrm{~cm}$ topsoil (zand-B2; Wösten et al., 1994) with a zand-O2 subsoil (290 cm; Wösten et al., 1994), with a free drainage bottom boundary condition. KNMI weather data from stations 370 (Eindhoven) and 918 (Maarheze; rainfall) were used. Figure 5a shows the good correspondence between measured and simulated groundwater levels.

a)

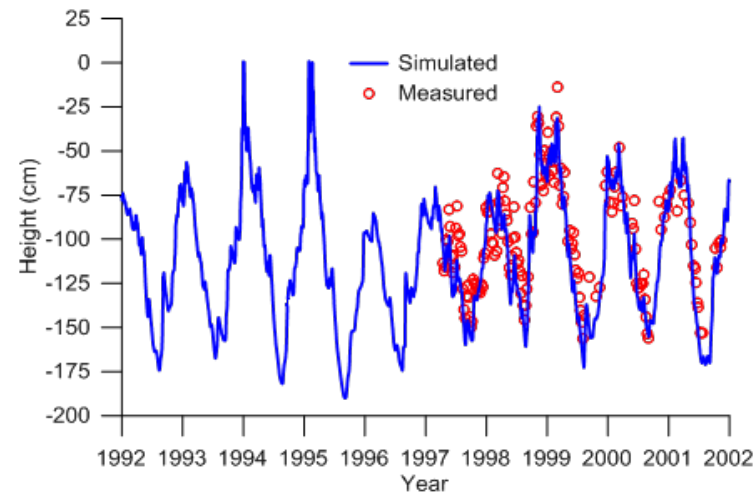

b)

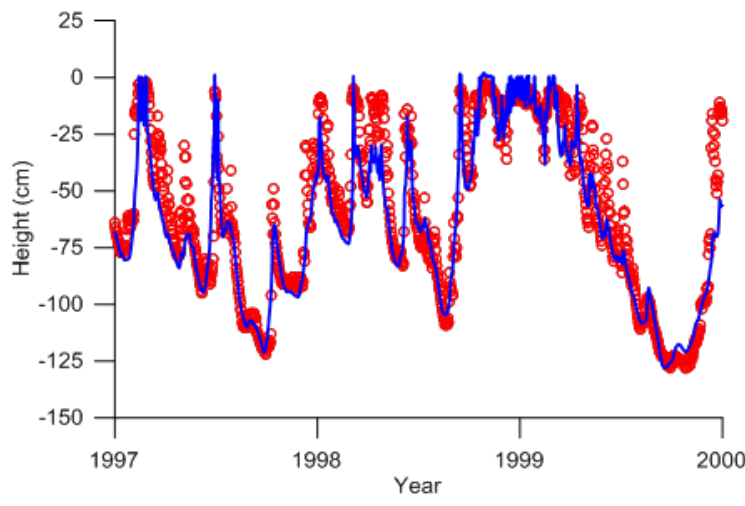

Figure 5. Comparison between measured and simulated groundwater levels for cases a) Cranendonck and b) Wildenbroch.

\subsubsection{Wildenborch}

This study was described by Massop et al. (2001) and the simulation was reported in van Dam et al. (2008). This study refers to a case with use of the extended drainage option in SWAP. For this purpose the internal simple grass growth option was used. The soil profile consisted of zand-B1 (0-25 cm; Wösten et al., 2001) and zand-O1 (25-405 cm; Wösten et al., 2001). A flux-type bottom boundary condition was used which followed from a hydraulic head of an underlying aquifer and a vertical resistance of a separating aquitard. Figure $\mathbf{5 b}$ shows the good correspondence between measured and simulated groundwater levels. 


\subsubsection{Castricum}

From a lysimeter experiment in Castricum the yearly amount of drainage and actual evaporation from bare soil was used to compare with SWAP simulations; description of and data from the lysimeter study was described in van der Hoeven (2011). The soil profile consisted of 0-35 cm zand-B1 (Wösten et al., 1994) and 35-250 cm zand-O1 (Wösten et al., 1994). A constant groundwater level at $225 \mathrm{~cm}$ below soil surface was used as bottom boundary condition. Local weather data were used. Figure 6 shows the good correspondence between measured and simulated drainage and evaporation.

a)

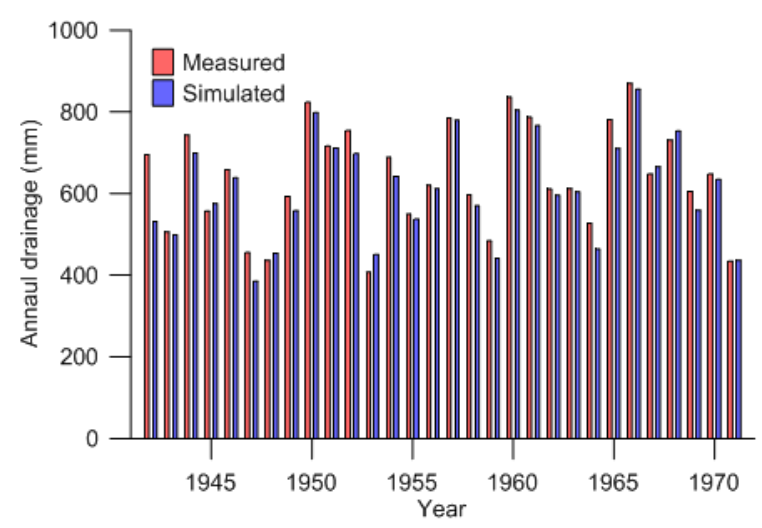

b)

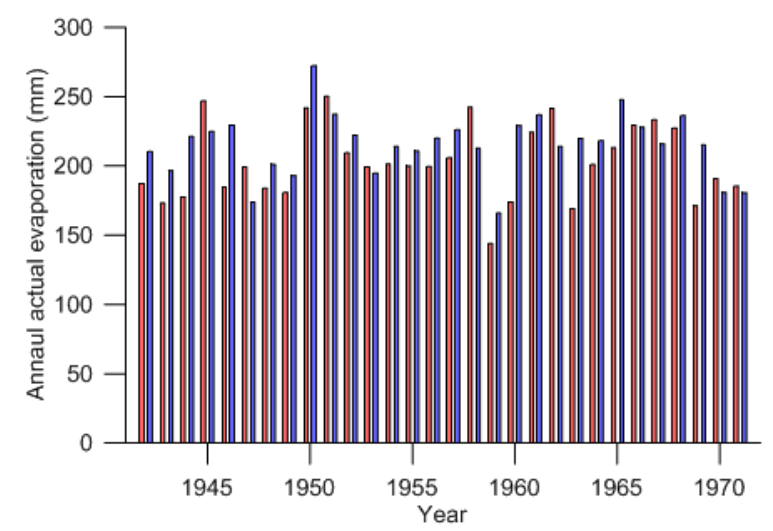

Figure 6. Comparison between measured and simulated a) annual drainage and b) annual evaporation from a bare-soil lysimeter for the Castricum case.

\subsubsection{Zegveld}

The Zegveld case refers to a wet grassland on peat with simple drainage (R. Hendriks, pers. comm.; see also Kroes et al., 2015). A flux-type bottom boundary condition was used which followed from a hydraulic head of an underlying aquifer and a vertical resistance of a separating aquitard. Figure 7 shows the correspondence between measured and simulated yields, groundwater levels and pressure head at $20 \mathrm{~cm}$ depth. Since this test case was included as a reference test case, the input variables have not been changed so that such changes do not interfere with possible changes in simulation result with each new release of SWAP. In a separate study Kroes et al. (2015) optimized the input data to obtain better correspondence between measured and simulated yields (Figure 8 ). 
a)

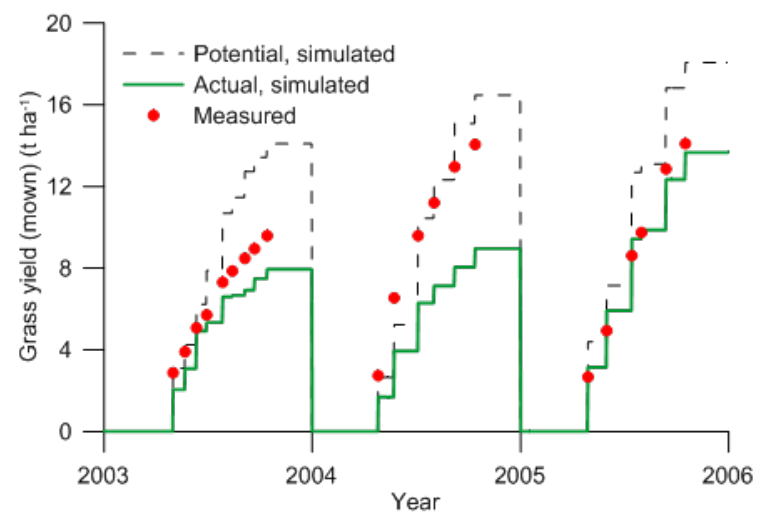

C)

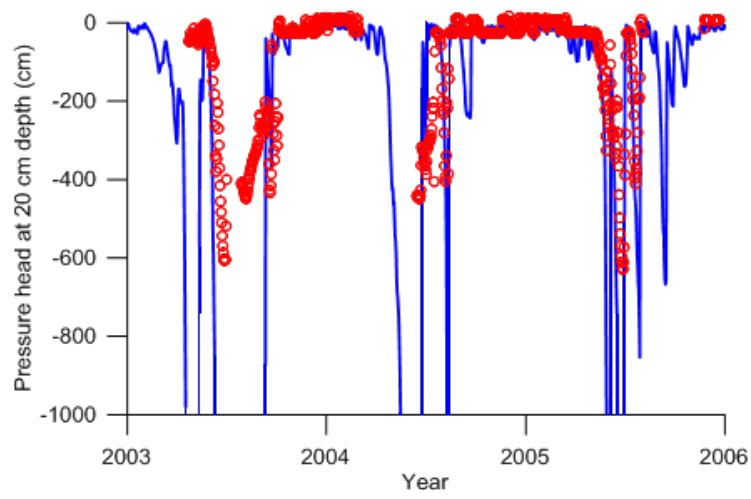

b)

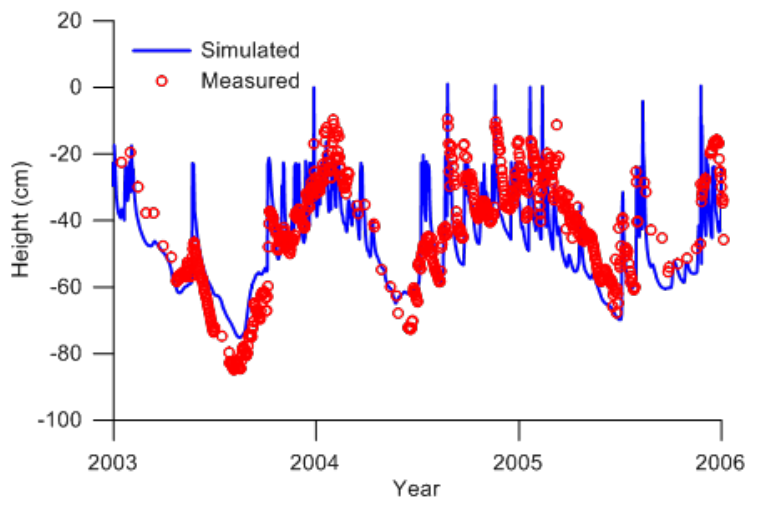

Figure 7. Comparison between measured and simulated data for the Zegveld case: a) grass yield, b) groundwater level, and c) pressure head at $20 \mathrm{~cm}$ depth. Note: common tensiometers to measure pressure heads can only be use down to approximately $-800 \mathrm{~cm}$.

Yield ; SIMmean 12804.67 ; OBSmean 12577 ; ME 227.67 ; kg/ha/yr DM

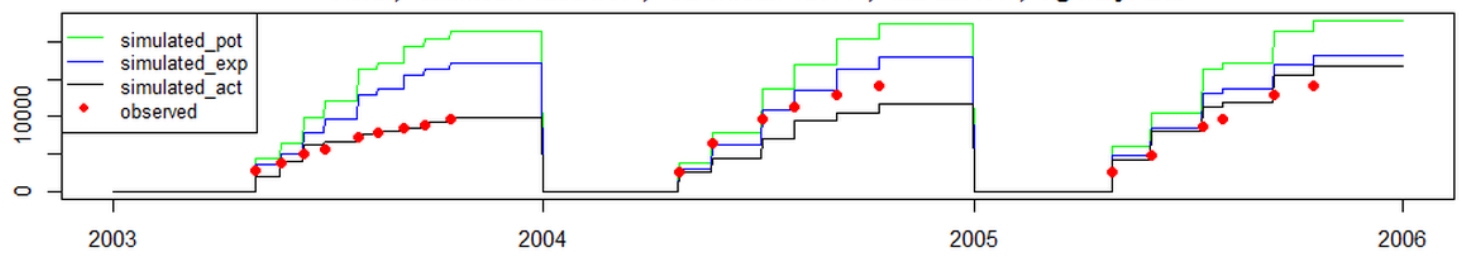

Figure 8. Comparison between measured and simulated grass yield for the Zegveld case by Kroes et al. (2015).

\subsubsection{Rusthoeve}

The Rusthoeve case was described in Schipper et al. (2015; their case 'blok7'). Three different crops were considered: sugar beet (2011), winter wheat (2011-2012) and potatoes (2013). The soil profile was 0-25 cm zavel-B9 (Wösten et al., 1994), 25-45 cm zavel-O10 (Wösten et al., 1994) and 45-545 cm zavel-09 (Wösten et al., 1994). A flux-type bottom boundary condition was used which followed from a hydraulic head of an underlying aquifer (measured, tabulated data) and a vertical resistance of a separating aquitard. Two drainage levels were considered: at $90 \mathrm{~cm}$ (drain tube distance $6 \mathrm{~m}$, drain 
resistance $66 \mathrm{~d}$ ) and at $130 \mathrm{~cm}$ (drain tube distance $100 \mathrm{~m}$, drain resistance $2500 \mathrm{~d}$ ). KNMI weather data from stations 310 (Vlissingen) and 755 (Kortgene; rainfall) were used.

Only for the last crop (potatoes) the yield was measured as $8.6 \mathrm{t} \mathrm{ha}^{-1}$, which was well simulated by the model: $8.7 \mathrm{t} \mathrm{ha}^{-1}$. Figure 9 shows the good correspondence between measured and simulated groundwater level and drain discharge.

a)

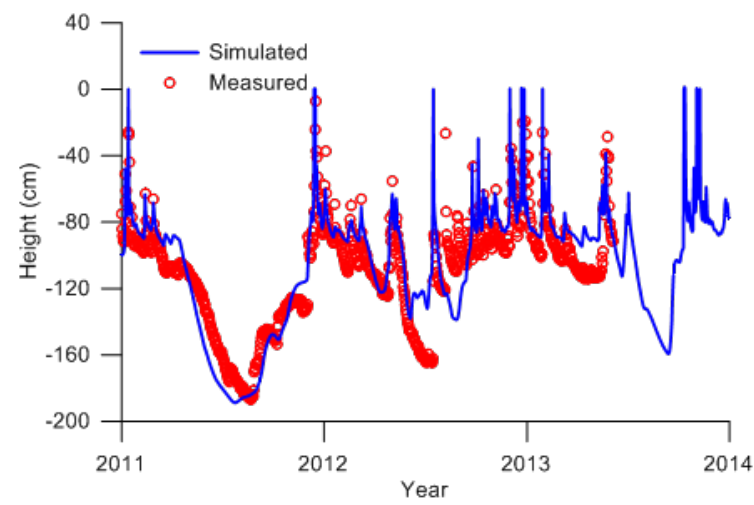

b)

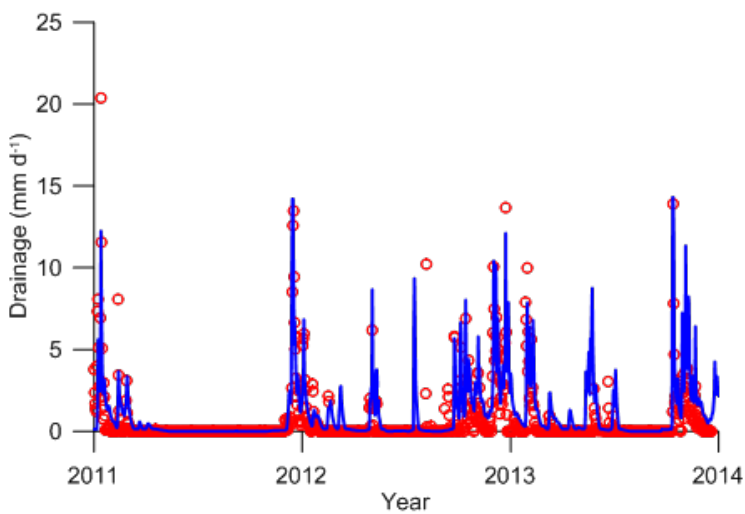

Figure 9. Measured and simulated a) groundwater level and b) drain discharge for the Rusthoeve case.

\subsubsection{Dijkgraaf}

The Dijkgraaf case is based on Elbers et al. (2010). The main crop was maize (end of May until beginning of October 2007) simulated as a default WOFOST crop. The remainder of the year the soil was covered by grass (simple grass growth option in SWAP). The soil profile was $0-25 \mathrm{~cm}$ zand-B2 (Wösten et al., 2001) and 25-300 cm zand-O2 (Wösten et al., 2001). A flux-type bottom boundary condition was used which followed from a hydraulic head of an underlying aquifer (sine function) and a vertical resistance of a separating aquitard. No lateral drainage was considered. Locally measured meteo data of Haarweg was used. Figure $\mathbf{1 0}$ shows the correspondence between measured and simulated crop data (yield, LAI), actual evapotranspiration, and volumetric water content at $20 \mathrm{~cm}$ depth.

a)

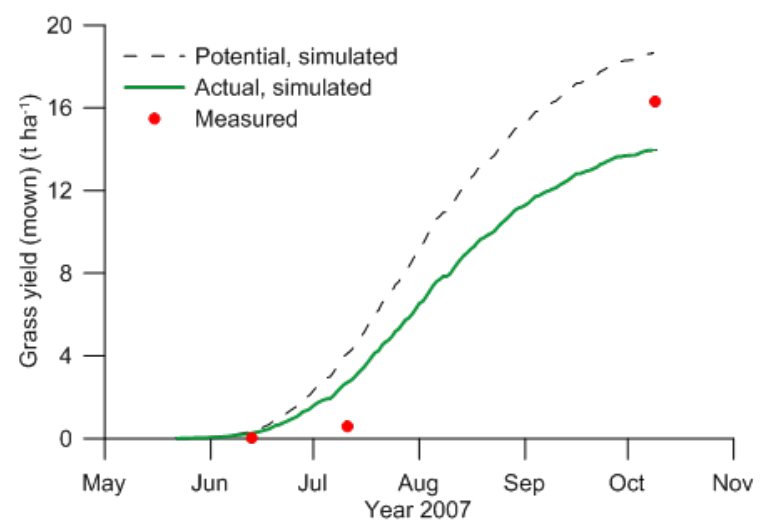

b)

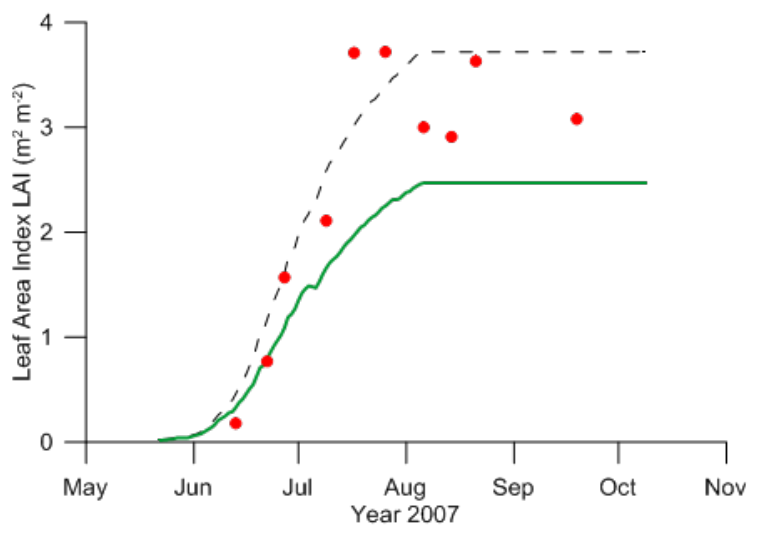


c)

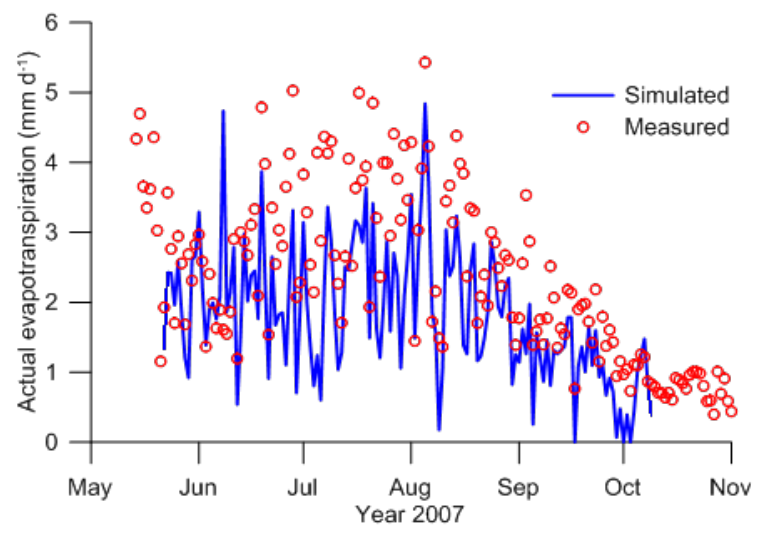

d)

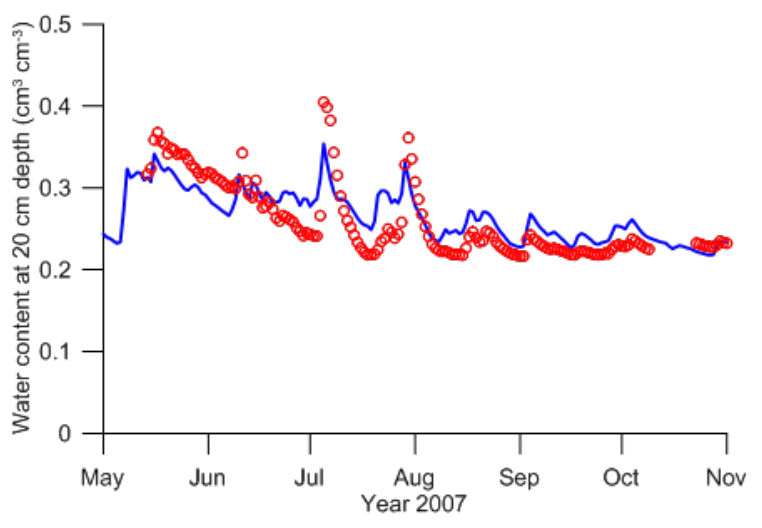

Figure 10. Measured and simulated a) maize yield, b) maize leaf area index, c) actual evapotranspiration, and d) volumetric water content at $20 \mathrm{~cm}$ depth for the Dijkgraaf case.

\subsubsection{Texel}

Mulder et al. (2018) validated SWAP-WOFOST for salinity stress in irrigated potatoes. Figure 11 shows an example of the good correspondence between simulated and measured salinity in the soil for the different irrigation salinity treatments. 
Salinity irrigationwater: 1.7 [dS $\mathrm{m}^{-1}$ ]

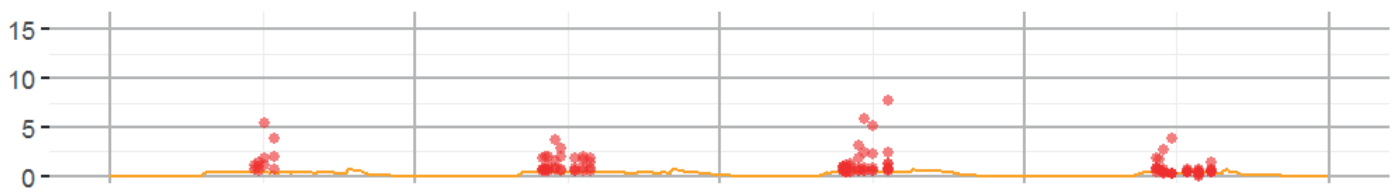

Salinity irrigationwater: 4 [dS $\mathrm{m}^{-1}$ ]

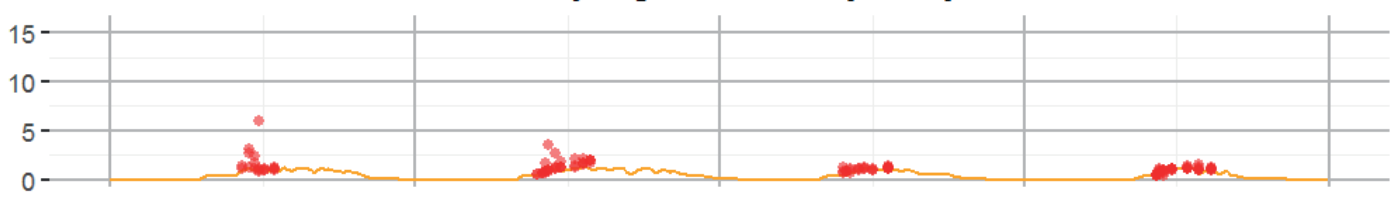

Salinity irrigationwater: 8 [dS $\left.\mathrm{m}^{-1}\right]$

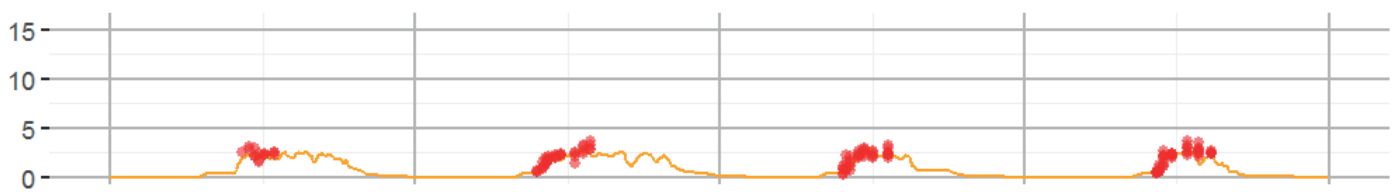

Salinity irrigationwater: 12 [dS $\mathrm{m}^{-1}$ ]

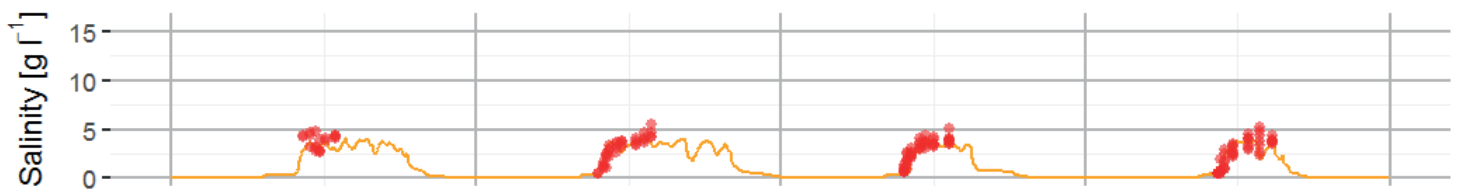

Salinity irrigationwater: 16 [dS $\mathrm{m}^{-1}$ ]

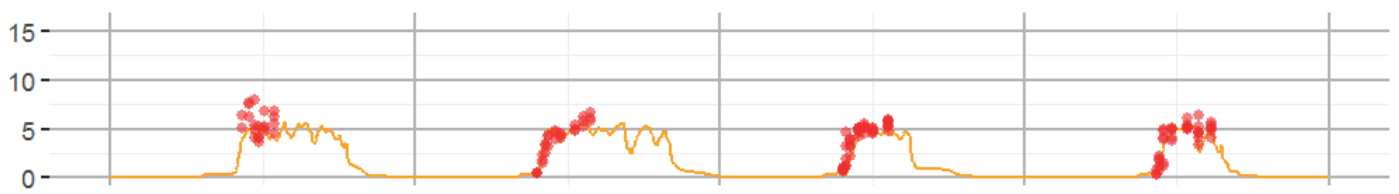

Salinity irrigationwater: 20 [dS $\mathrm{m}^{-1}$ ]

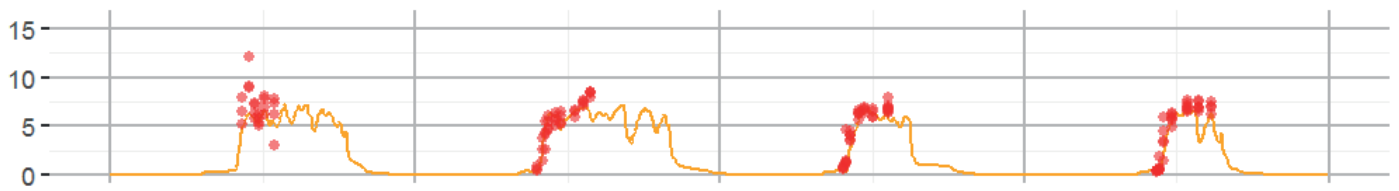

Salinity irrigationwater: 35 [dS ${ }^{-1}$ ]

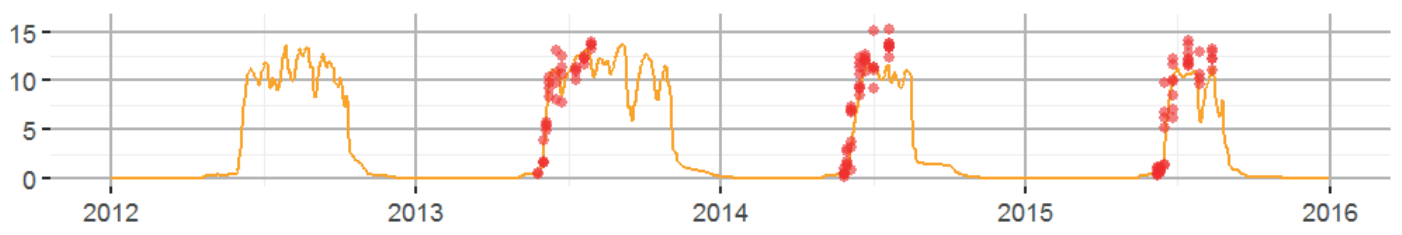

Figure 11. Measured (symbols) and simulated (lines) salinity of the pore water at depth $20-30 \mathrm{~cm}$ for treatments with irrigation water with different salinity concentrations (1.7 to $35 \mathrm{dS} \mathrm{m}^{-1}$, from top to bottom) (from: Mulder et al., 2018). 


\subsection{Applications in literature}

SWAP has been used extensively in scientific literature, where it is used either with or without comparison to field data or where it is used in a comparison against other models. On the website swap.wur.nl a detailed list of literature is given, divided in the following subject areas:

1. General reference to SWAP

2. On the use of SWAP

3. Soil water flow

4. Evapotranspiration

5. Irrigation management

6. Drainage conditions

7. Surface water management

8. Plant growth

9. Soil water extraction by roots

10. Soil moisture indicators for natural vegetation

11. Salinization

12. Solute transport

13. Soil water flow as affected by soil spatial heterogeneity

14. Sensitivity analysis

15. Regional analysis

16. Integration with other models

\subsection{Resume}

The main core of SWAP is the numerical solution of the governing partial differential equation for water movement in porous media. It requires information on the (highly) non-linear, constitutive relationships between the pressure head, volumetric water content and hydraulic conductivity (i.e. water retention and hydraulic conductivity characteristics). SWAP is set-up such that the user (modeller) needs to provide information on soil properties and to define proper initial and boundary conditions. How good the simulation results obtained with SWAP are, depends on these input data. Verification and validation tests are helpful in getting confidence in the SWAP model.

In Section 3.1 a SWAP simulation was verified against a transient analytical solution for infiltration in a layered soil, showing that the technical numerical implementation of the solution of the partial differential equation is valid. Such tests have also been performed for solute transport and soil temperature (Heinen et al., 2021b).

Comparing SWAP simulations with measured field data can be seen as validation. In Section 3.2 seven examples are provided in which comparison is done on groundwater levels, drainage and evaporation from a lysimeter, yield (grass including cuttings; maize), pressure head or volumetric water content at a certain depth, drain discharge, actual evapotranspiration, and salinity of the pore water at a certain depth. Other than for the comparison with analytical solutions, such validation experiments mostly don't show an exact agreement between simulated and measured data. Then the focus is more on agreement in trends and order of magnitude.

SWAP is used extensively in studies reported in scientific literature for a wide range of subjects (see Section 3.3). These can also be seen as examples of validation. 


\section{Sensitivity analysis}

\subsection{Introduction}

Numerical simulation models are by definition approximations of reality. The outcome of model predictions highly depends on the boundary conditions, initial condition, model parameters, and on the numerical discretization (both in space and in time). The processes considered in SWAP, i.c. water movement and solute transport, are highly non-linear. Therefore, finding out the sensitivity of the model with respect to its model input cannot be determined analytically. Especially not for time-dependent, dynamic situations. For specifically defined situations analytical solutions for steady-state situations are sometimes available.

Since the number of input variables and choices in sub-processes in SWAP is rather large, there is no unique simple sensitivity procedure available, nor has it been carried out in detail. It is suggested that for each study the modeller performs a problem-unique sensitivity analysis to determine which input variables need to be determined in detail.

This chapter will provide the following sensitivity analyses:

- the effect of spatial and temporal discretization of the SWAP model based on two analytical, steady-state situations for water movement (Section 4.2) and solute transport (Section 4.3);

- the effect of spatial and temporal discretization for an infiltration-runoff situation supplemented by analytical expressions of the sensitivity of the runoff equation (Section 4.4);

- the effect of spatial discretization upon a capillary rise situation (Section 4.5);

- a Monte-Carlo type sensitivity analysis for a set of input parameters from the Watervision Agriculture project (Section 4.6);

- brief descriptions of sensitivity analyses using SWAP performed in scientific literature (Section 4.7).

\subsection{Steady-state water movement}

This example is based on one of the default test cases to which each new release of SWAP is tested. It refers to a steady-state infiltration problem in a soil column consisting of two contrasting soil layers. The problem is fully described in Vanderborght et al. (2005). The steady-state solution is given by:

$$
\Delta z=z_{1}-z_{2}=-\int_{h\left(z_{2}\right)}^{h\left(z_{1}\right)} \frac{K(h)}{I-K(h)} \mathrm{d} h
$$

where $z$ is the soil depth $(\mathrm{cm}), h$ is the pressure head $(\mathrm{cm}), K$ is the hydraulic conductivity $\left(\mathrm{cm} \mathrm{d}^{-1}\right)$, and $I$ is the infiltration rate $\left(\mathrm{cm} \mathrm{d}^{-1}\right)$. No analytical solution is available to solve Eq. (3), so that it is numerically approximated by increasing $z$ starting at the bottom of the soil profile with small steps in $\Delta z$ (e.g. $2^{-13} \mathrm{~cm}$ ) until soil surface is reached, and where the hydraulic properties change at the interface of the soil layers. The pressure head at the bottom (total soil depth $200 \mathrm{~cm}$ ) was obtained from the hydraulic conductivity relationship such that $K(h)=I$ (unit gradient bottom boundary condition). For each new depth $z$ the corresponding $h$ follows then from

$$
h(z)=h(z-\mathrm{d} z)-\mathrm{d} z\left(\frac{I}{K(h(z-\mathrm{d} z))}+1\right)
$$


Three situations were considered ${ }^{1}: 49.5 \mathrm{~cm}$ clay on sand and $49.5 \mathrm{~cm}$ sand on loam and $49.5 \mathrm{~cm}$ loam on sand. The constant infiltration rate was $I=0.5 \mathrm{~cm} \mathrm{~d}^{-1}$ and the Mualem-van Genuchten parameters for the soils are listed in Table 1.

Table 1. Mualem-van Genuchten parameters for three soils used in the example of steady-state water movement.

\begin{tabular}{|lllll|l|r|} 
Soil & $\begin{array}{l}\theta_{\mathrm{r}} \\
\left(\mathrm{m}^{3} \mathrm{~m}^{-3}\right)\end{array}$ & $\begin{array}{l}\theta_{\mathrm{s}} \\
\left(\mathrm{m}^{3} \mathrm{~m}^{-3}\right)\end{array}$ & $\begin{array}{l}\alpha \\
\left(\mathrm{cm}^{-1}\right)\end{array}$ & $\begin{array}{l}n \\
(-)\end{array}$ & $\begin{array}{l}\lambda \\
(-)\end{array}$ & \multicolumn{1}{c}{$\begin{array}{l}K_{\mathrm{s}} \\
\left(\mathrm{cm} \mathrm{d}^{-1}\right)\end{array}$} \\
\hline Clay & 0.1 & 0.4 & 0.01 & 1.1 & 0.5 & 10 \\
\hline Loam & 0.080 & 0.43 & 0.04 & 1.6 & 0.5 & 50 \\
\hline Sand & 0.045 & 0.43 & 0.15 & 3.0 & 0.5 & 1000
\end{tabular}

The infiltration started at $t=0$, and the simulated steady-state profiles were obtained at $t=365 \mathrm{~d}$. Simulation were performed for the following spatial discretizations of the soil profile: $\Delta z=0.5 \mathrm{~cm}, 1.0$ $\mathrm{cm}, 2.0 \mathrm{~cm}$ and $5.0 \mathrm{~cm}$. In all cases the first layer was always $0.5 \mathrm{~cm}$ thick; therefore, for the third discretization the second layer was set equal to $1 \mathrm{~cm}$, and for the fourth discretization the layers 2-5 were set equal to $1 \mathrm{~cm}$ (Table 2 ).

Table 2. Layer thickness for the four cases considered.

\begin{tabular}{l|l}
\multicolumn{2}{l}{ Casus } \\
\hline$\Delta z=0.5 \mathrm{~cm}$ & $\Delta z=0.5,98 * 0.5,300 * 0.5 \mathrm{~cm}$ \\
\hline$\Delta z=1.0 \mathrm{~cm}$ & $\Delta z=0.5,49 * 1.0,150 * 1.0 \mathrm{~cm}$ \\
\hline$\Delta z=2.0 \mathrm{~cm}$ & $\Delta z=0.5,1.0,24 * 2.0,75 * 2.0 \mathrm{~cm}$ \\
\hline$\Delta z=5.0 \mathrm{~cm}$ & $\Delta z=0.5,4 * 1.0,9 * 5.0,30 * 5.0 \mathrm{~cm}$ \\
\hline
\end{tabular}

Figure 12 presents the comparison between the simulated and analytical solutions for both cases (some statistics in Table 3). For the cases clay-on-sand and loam-on-sand the pressure head profiles in the clay and loam top soils moderately change towards the layer interface, and we do not see big differences between the spatial discretizations employed. For the sand-on-loam case there is a sharp infiltration front near the layer interface. For this case a big effect of the chosen discretization is seen, where the coarser discretizations differ markedly from the analytical solution.

\footnotetext{
${ }^{1}$ In Vanderborght et al. (2005) the first layer was $50 \mathrm{~cm}$ thick; here $49.5 \mathrm{~cm}$ is used corresponding to the first test case of SWAP, where it was chosen to have the first layer equal to $0.5 \mathrm{~cm}$ (see later) followed by layers of $1 \mathrm{~cm}$ resulting in the default test case having the first soil layer being $49.5 \mathrm{~cm}$. Note that erroneously in the first test case of SWAP the SWAP results are compared to the analytical solution with first soil layer equal to 50 $\mathrm{cm}$ (instead of $49.5 \mathrm{~cm}$ ).
} 
a) Clay on sand

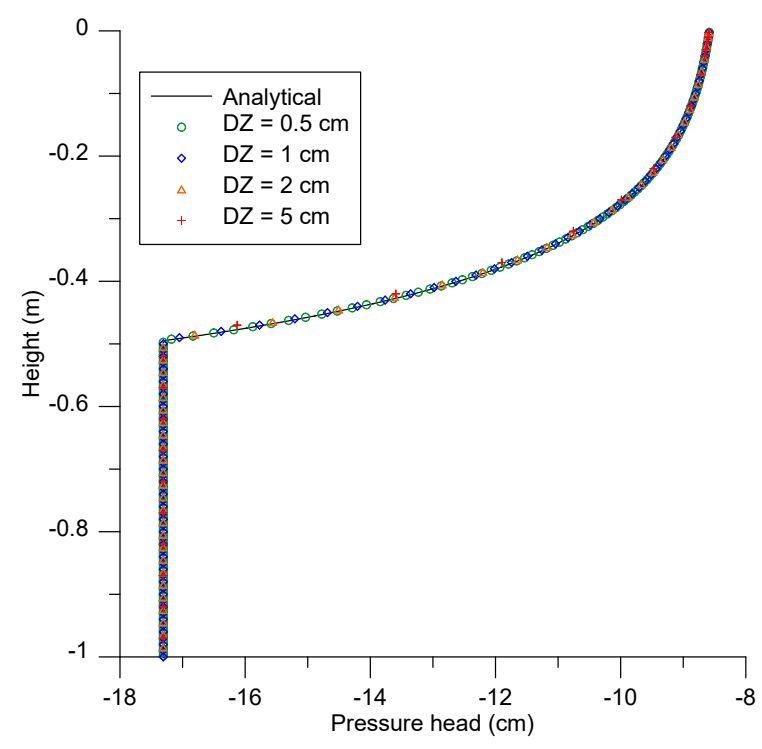

c) Loam on sand

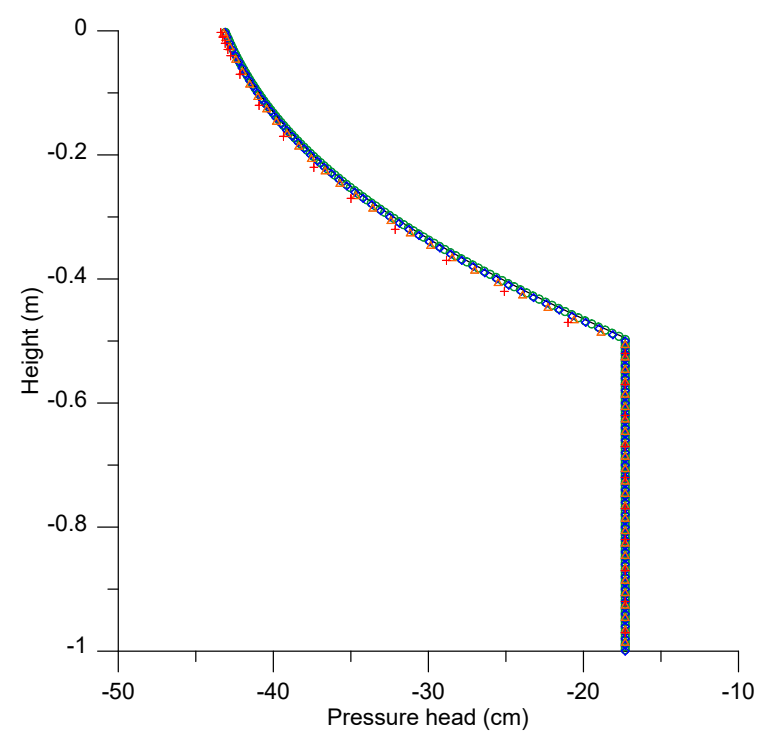

b) Sand on loam

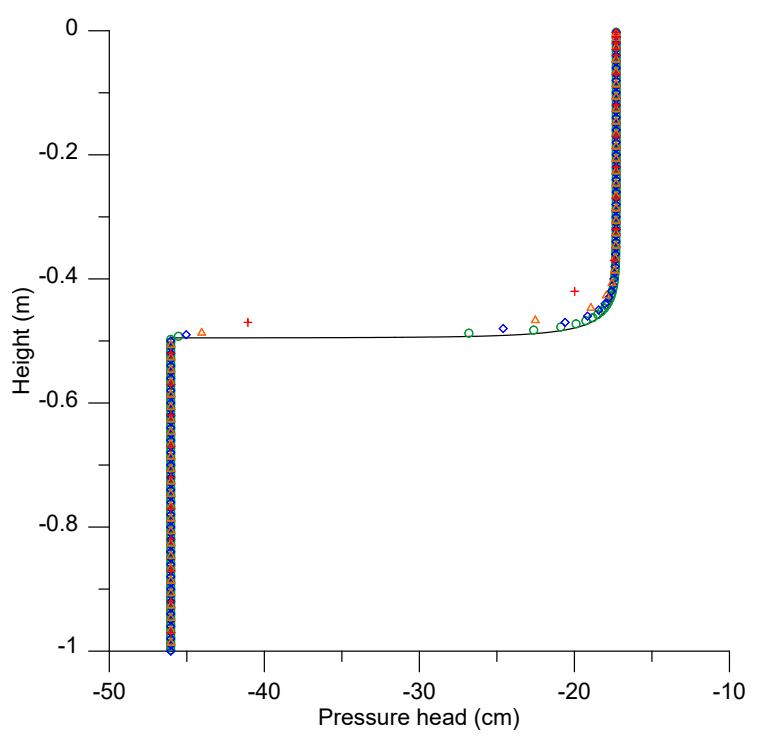

d) Sand on loam, 2

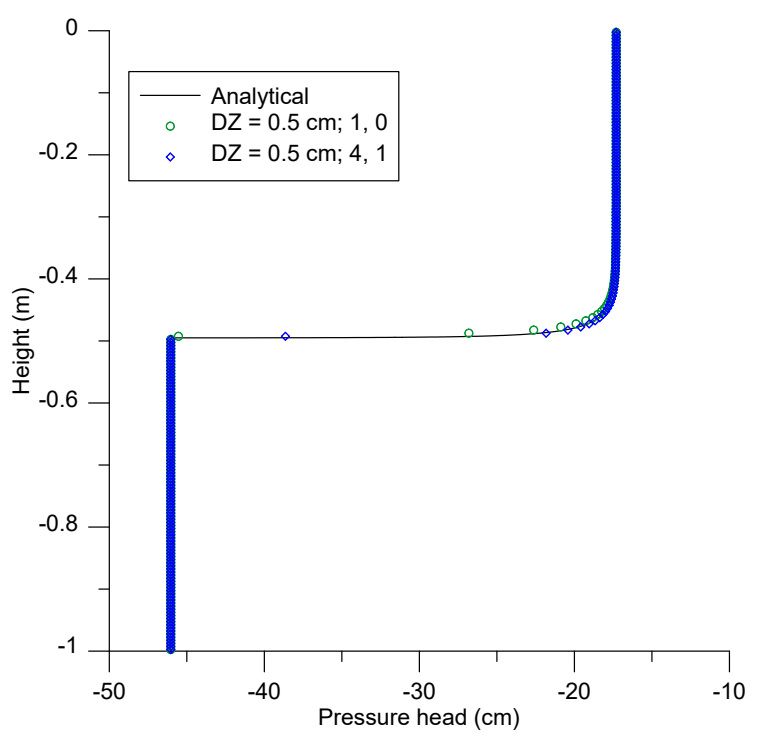

Figure 12. Steady-state pressure head - depth profiles for infiltration in a tow-layered soil for four spatial discretizations used in the SWAP model versus the analytical solution (Eq. (3)-(4)): a) clay on sand, b) sand on loam, c) loam on sand, an d) a second case for Sand on loam (see text for explanation).

For the case sand-on-loam an additional simulation was performed with thin layers $(\Delta z=0.5 \mathrm{~cm})$ for which in the numerical solution of SWAP the unknown hydraulic conductivity $K$ is taken implicitly into account during the iterative solution (swkimpl =1 (default 0 )) and where the hydraulic conductivity at the interfaces of the grid layers is calculated as the geometric average of the two neighbouring nodes (swkmean $=4$ (default 0$)$ ). An improvement can be seen in the performance (Figure 12d; new case denoted as $\Delta z=0.5 \mathrm{~cm} ; 4,1)$.

These examples show that spatial discretization can be important for situation where one expects great gradients in the soil profile. 
Table 3. Statistics Pearson r (squared), and (normalized) root mean square error ((N)RMSE) for the cases considered.

\begin{tabular}{|c|c|c|c|c|}
\hline \multirow{2}{*}{ Clay on sand } & & \multirow{2}{*}{$\begin{array}{l}\text { r2 } \\
0.99999422\end{array}$} & \multirow{2}{*}{$\begin{array}{l}\text { RMSE } \\
0.00837516\end{array}$} & \multirow{2}{*}{$\begin{array}{l}\text { NRMSE } \\
-0.0005351\end{array}$} \\
\hline & $\Delta z=0.5 \mathrm{~cm}$ & & & \\
\hline & $\Delta z=1 \mathrm{~cm}$ & 0.99997646 & 0.01691932 & -0.0010822 \\
\hline & $\Delta z=2 \mathrm{~cm}$ & 0.99990469 & 0.03439019 & -0.0022096 \\
\hline & $\Delta z=5 \mathrm{~cm}$ & 0.99948908 & 0.08712751 & -0.0058113 \\
\hline \multirow[t]{5}{*}{ Sand on loam } & $\Delta z=0.5 \mathrm{~cm}$ & 0.99349494 & 0.99444810 & -0.0255111 \\
\hline & $\Delta z=1 \mathrm{~cm}$ & 0.98433017 & 1.55059503 & -0.0398373 \\
\hline & $\Delta z=2 \mathrm{~cm}$ & 0.96551420 & 2.39529978 & -0.0629153 \\
\hline & $\Delta z=5 \mathrm{~cm}$ & 0.93828292 & 3.35722739 & -0.0908891 \\
\hline & $\Delta z=0.5 \mathrm{~cm} ; 4,1$ & 0.99750619 & 0.61458293 & -0.0157662 \\
\hline \multirow[t]{4}{*}{ Loam on sand } & $\Delta z=0.5 \mathrm{~cm}$ & 0.99997331 & 0.05660822 & -0.0026558 \\
\hline & $\Delta z=1 \mathrm{~cm}$ & 0.99989836 & 0.11171485 & -0.0052278 \\
\hline & $\Delta z=2 \mathrm{~cm}$ & 0.99963934 & 0.21714007 & -0.0100602 \\
\hline & $\Delta z=5 \mathrm{~cm}$ & 0.99869288 & 0.49036569 & -0.0210330 \\
\hline
\end{tabular}

\subsection{Steady-state solute transport}

This example is based on one of the default test cases to which each new release of SWAP is tested. For a soil column with uniform downward water movement and where a pulse of a solute is applied at the soil surface, the concentration inside the soil column can be analytically described as a function of time and depth (Kroes and Rijtema, 1996; based on Jury and Roth, 1990):

$$
c=\frac{M}{\theta R} \exp [-k t]\left(\frac{1}{\sqrt{\pi D \frac{t}{R}}} \exp \left[-\frac{\left(z-v \frac{t}{R}\right)^{2}}{4 D \frac{t}{R}}\right]-\frac{v}{2 D} \exp \left[\frac{v z}{D}\right] \operatorname{erfc}\left[\frac{z+v \frac{t}{R}}{\sqrt{4 D \frac{t}{R}}}\right]\right)
$$

where $c$ is the solute concentration in the liquid phase $\left(\mathrm{mg} \mathrm{mL}^{-1}\right), M$ is the areic mass of solute applied during the pulse $\left(\mathrm{mg} \mathrm{cm}^{-2}\right), \theta$ is the volumetric water content $\left(\mathrm{cm}^{3} \mathrm{~cm}^{-3}\right), R$ is the retardation factor $(-)$, $k$ is a decay coefficient $\left(\mathrm{d}^{-1}\right), t$ is the time $(\mathrm{d}), v$ is the pore water velocity $\left(\mathrm{cm} \mathrm{d}^{-1} ; v=q / \theta\right.$, with $q$ the soil water flux density $\left.\mathrm{cm}^{3} \mathrm{~cm}^{-2} \mathrm{~d}^{-1}\right), z$ is the soil depth $(\mathrm{cm})$, and $D$ is the apparent dispersion-diffusion coefficient $\left(\mathrm{cm}^{2} \mathrm{~d}^{-1}\right)$ here with $D=v L_{\text {dis, }}$ with $L_{\text {dis }}$ the dispersion length $(\mathrm{cm})$. Here we consider: $q=0.1$ $\mathrm{cm}^{3} \mathrm{~cm}^{-2} \mathrm{~d}^{-1}, \theta=0.319 \mathrm{~cm}^{3} \mathrm{~cm}^{-3}, M=31.9 \mathrm{mg} \mathrm{cm}^{-2}$ ( $c$ of pulse: $c_{0}=319 \mathrm{mg} \mathrm{mL}^{-1}$; pulse duration $t_{0}=1$ $\left.\mathrm{d} ; M=q c_{0} t_{0}\right), R=1$ (no retardation), $k=0 \mathrm{~d}^{-1}$ (no decay), and three values for $L_{\text {dis }}: 0.1 \mathrm{~cm}, 1 \mathrm{~cm}$, and $10 \mathrm{~cm}$. The soil profile was $200 \mathrm{~cm}$ long with uniform soil type (Table 4) and different spatial discretizations were used: $\Delta z=0.1 \mathrm{~cm}, 0.5 \mathrm{~cm}, 1 \mathrm{~cm}, 2 \mathrm{~cm}$ and $5 \mathrm{~cm}$. The concentration profile refer to $t=30 \mathrm{~d}$ (Figure 13). For the case with a relative high dispersion length $\left(L_{\mathrm{dis}}=10 \mathrm{~cm}\right.$; Figure 13c) the discretization visibly has no effect on the solute profile in the soil column. However, for a small dispersion length ( $L_{\text {dis }}=0.1 \mathrm{~cm}$; Figure 13a) the coarser discretizations result in more flattening of the concentration profile (lower maximum concentration; more flattening at the upper and bottom tails); the case with dispersivity of $1 \mathrm{~cm}$ shows an intermediate behaviour (Figure 13b). Some statistics are provided in Table $\mathbf{5}$.

Vanderborght and Vereecken (2007) reviewed dispersivities for one-dimensional modelling. The dispersivities reported from field studies were on average several tens of centimetres (up to several hundred centimetres), whereas those for soil cores a small soil columns were about $10 \mathrm{~cm}$ or slightly less (in line with an earlier review by Beven et al., 1993). Since most studies with SWAP-WOFOST will be focussing on the field scale, the larger dispersivities will be used, for which in this example no effect of 
the spatial discretization was observed. In fact, in SWAP the numerical dispersion is taken into account when solving the solute transport equation, thus minimizing the contribution of numerical dispersion.

Table 4. Constant pressure head and Mualem-van Genuchten parameters for three soils used in the example of steady-state solute transport.

\begin{tabular}{|c|c|c|c|c|c|c|}
\hline $\begin{array}{l}h_{\text {ini }} \\
(\mathbf{c m})\end{array}$ & $\begin{array}{l}\theta_{r} \\
\left(m^{3} m^{-3}\right)\end{array}$ & $\begin{array}{l}\theta_{s} \\
\left(m^{3} m^{-3}\right)\end{array}$ & $\begin{array}{l}\alpha \\
\left(\mathrm{cm}^{-1}\right)\end{array}$ & $\begin{array}{l}n \\
(-)\end{array}$ & $\begin{array}{l}\lambda \\
(-)\end{array}$ & $\begin{array}{l}K_{s} \\
\left(\mathrm{~cm} \mathrm{~d}^{-1}\right)\end{array}$ \\
\hline-35.5429 & 0.08 & 0.43 & 0.04 & 1.6 & 0.5 & 5 \\
\hline
\end{tabular}

a) $L_{\text {dis }}=0.1 \mathrm{~cm}$

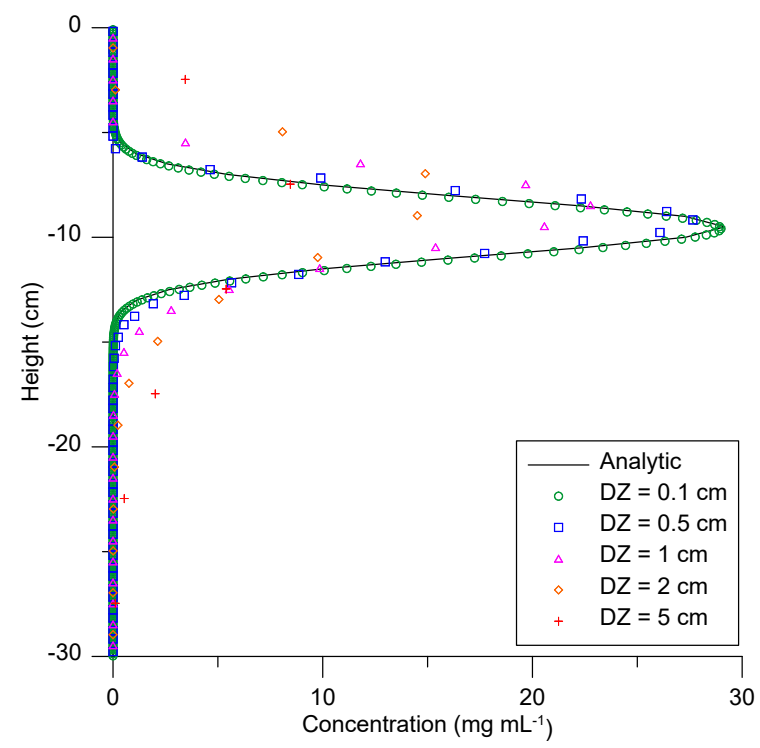

c) $L_{\text {dis }}=10 \mathrm{~cm}$

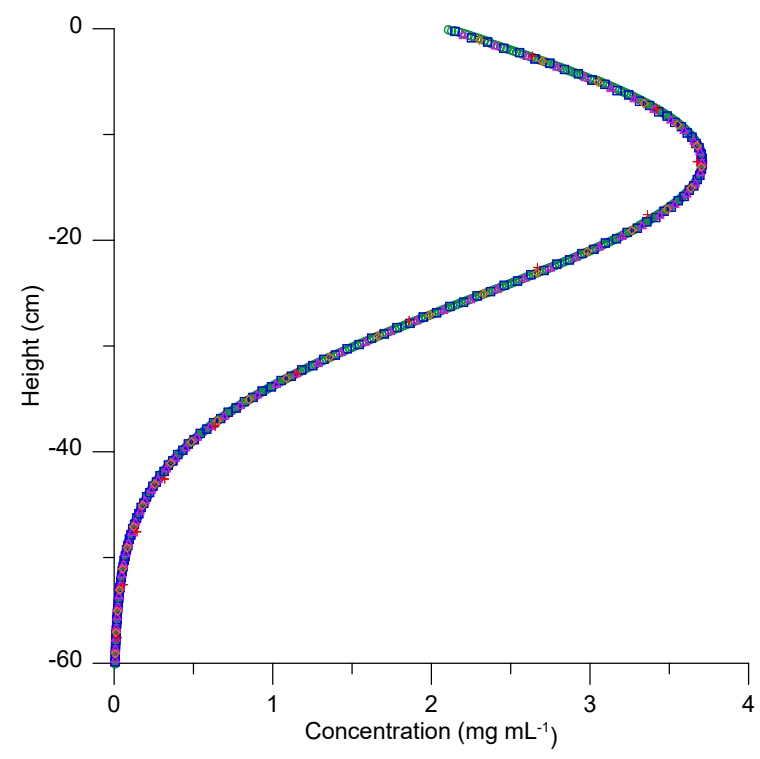

b) $L_{\text {dis }}=10 \mathrm{~cm}$

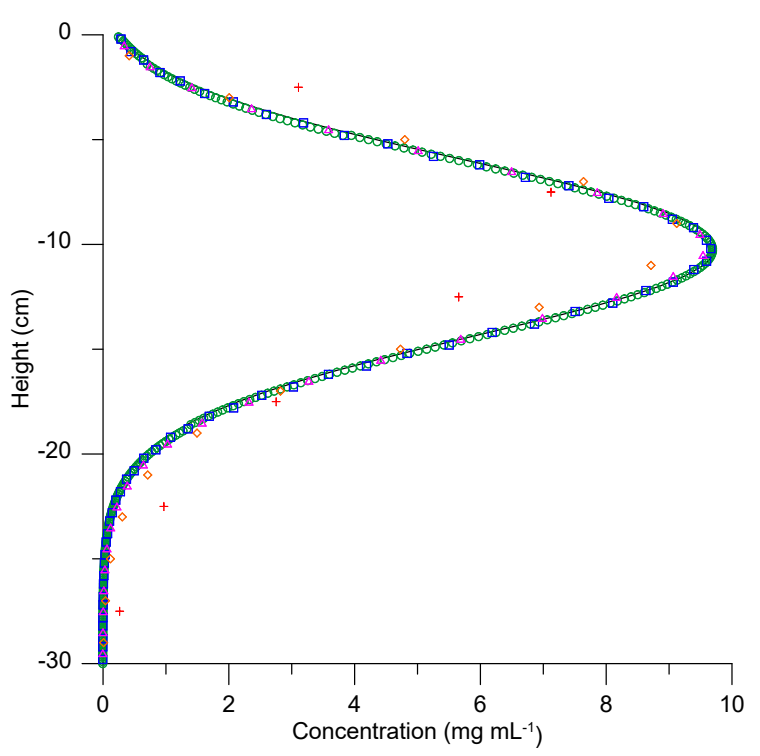

Figure 13. Concentration-depth profiles $30 d$ after a one day solute input under steady-state water movement for three dispersivities as a function of spatial discretization in the SWAP model compared to an analytical solution: a) 0.1 $\mathrm{cm}$, b) $1 \mathrm{~cm}$, and c) $10 \mathrm{~cm}$. 
Table 5. Statistics Pearson r (squared), and (normalized) root mean square error ((N)RMSE) for the cases considered.

\begin{tabular}{|c|c|c|c|c|}
\hline & & r2 & RMSE & NRMSE \\
\hline \multirow[t]{5}{*}{$L_{\text {dis }}=0.1 \mathrm{~cm}$} & $\Delta z=0.1 \mathrm{~cm}$ & 0.997346845 & 0.229794405 & 0.230007779 \\
\hline & $\Delta z=0.5 \mathrm{~cm}$ & 0.984224223 & 0.560439783 & 0.560439783 \\
\hline & $\Delta z=1 \mathrm{~cm}$ & 0.833104144 & 1.822663806 & 1.822663806 \\
\hline & $\Delta z=2 \mathrm{~cm}$ & 0.617049228 & 2.754858745 & 2.754833446 \\
\hline & $\Delta z=5 \mathrm{~cm}$ & 0.773546312 & 1.144214631 & 1.8264901 \\
\hline \multirow[t]{5}{*}{$L_{\text {dis }}=1 \mathrm{~cm}$} & $\Delta z=0.1 \mathrm{~cm}$ & 0.999494053 & 0.057630798 & 0.057557916 \\
\hline & $\Delta z=0.5 \mathrm{~cm}$ & 0.999332376 & 0.066081924 & 0.066082454 \\
\hline & $\Delta z=1 \mathrm{~cm}$ & 0.999494165 & 0.064831472 & 0.064824863 \\
\hline & $\Delta z=2 \mathrm{~cm}$ & 0.993255422 & 0.218658994 & 0.218571829 \\
\hline & $\Delta z=5 \mathrm{~cm}$ & 0.92003894 & 0.764808386 & 0.763239486 \\
\hline \multirow[t]{5}{*}{$L_{d i s}=10 \mathrm{~cm}$} & $\Delta z=0.1 \mathrm{~cm}$ & 0.999769392 & 0.023435979 & 0.023495596 \\
\hline & $\Delta z=0.5 \mathrm{~cm}$ & 0.999813506 & 0.022014058 & 0.022014215 \\
\hline & $\Delta z=1 \mathrm{~cm}$ & 0.999819485 & 0.021910069 & 0.021908119 \\
\hline & $\Delta z=2 \mathrm{~cm}$ & 0.999811897 & 0.022773201 & 0.02276509 \\
\hline & $\Delta z=5 \mathrm{~cm}$ & 0.999650742 & 0.039009147 & 0.038921782 \\
\hline
\end{tabular}

\subsection{Infiltration-runoff}

This example is based on one of the default test cases to which each new release of SWAP is tested (based on van Dam and Feddes, 2000). In a uniform soil with uniform pressure head (Table 6) a single rain event is considered: $100 \mathrm{~mm}$ in $2.4 \mathrm{~h}(0.1 \mathrm{~d})$. The focus is on the infiltration flux at the soil surface and the amount of runoff. Comparisons are done for different discretizations of the soil column: $\Delta z=0.1$ $\mathrm{cm}, 0.5 \mathrm{~cm}, 1 \mathrm{~cm}, 2 \mathrm{~cm}$ and $5 \mathrm{~cm}$ (all at $\Delta t_{\min }=10^{-6} \mathrm{~d}$ ); and for different minimum (initial) time steps: $\Delta t_{\min }=10^{-6} \mathrm{~d}, 10^{-5} \mathrm{~d}, 10^{-4}, 10^{-3}$ and $10^{-2} \mathrm{~d}$ (all at $\Delta z=1 \mathrm{~cm}$ ).

The infiltration flux at the soil surface, the flux of runoff at the soil surface and the cumulative runoff for are presented in Figure 14: panels a), c) and e) refer to the dependency on spatial discretization, and panels b), d) and f) refer to the dependency on minimum time step. Coarser spatial discretization result in lower predictions of runoff, and larger minimum (initial) time steps result in higher predicted runoff. It should be noted that for the cases $\Delta t_{\min }=10^{-4}, 10^{-3}$ and $10^{-2} \mathrm{~d}$ there were increasing mass balance errors in the calculations.

Table 6. Initial pressure head and Mualem-van Genuchten parameters for three soils used in the example of infiltration-runoff test.

\begin{tabular}{|c|c|c|c|c|c|c|}
\hline $\begin{array}{l}h_{\text {ini }} \\
(\mathbf{c m})\end{array}$ & $\begin{array}{l}\theta_{r} \\
\left(m^{3} m^{-3}\right)\end{array}$ & $\begin{array}{l}\theta_{s} \\
\left(m^{3} m^{-3}\right)\end{array}$ & $\begin{array}{l}\alpha \\
\left(\mathrm{cm}^{-1}\right)\end{array}$ & $\begin{array}{l}n \\
(-)\end{array}$ & $\begin{array}{l}\lambda \\
(-)\end{array}$ & $\begin{array}{l}K_{s} \\
\left(\mathrm{~cm} \mathrm{~d}^{-1}\right)\end{array}$ \\
\hline-832.5 & 0.01 & 0.43 & 0.0249 & 1.507 & -0.14 & 17.5 \\
\hline
\end{tabular}


a)

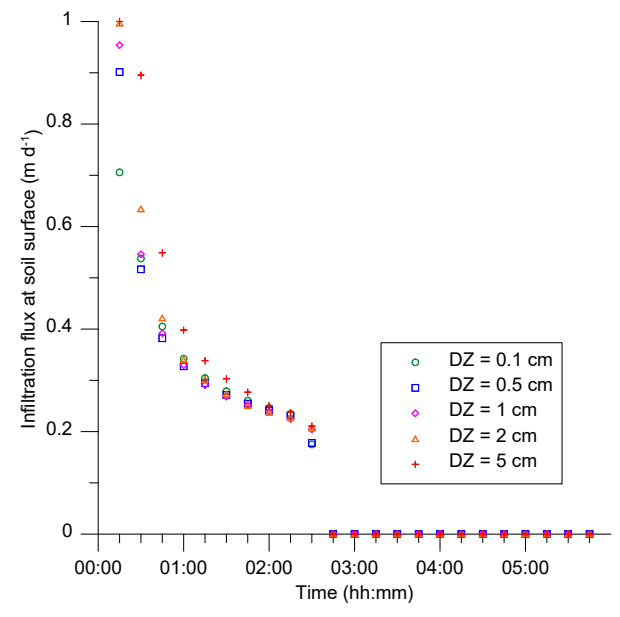

c)

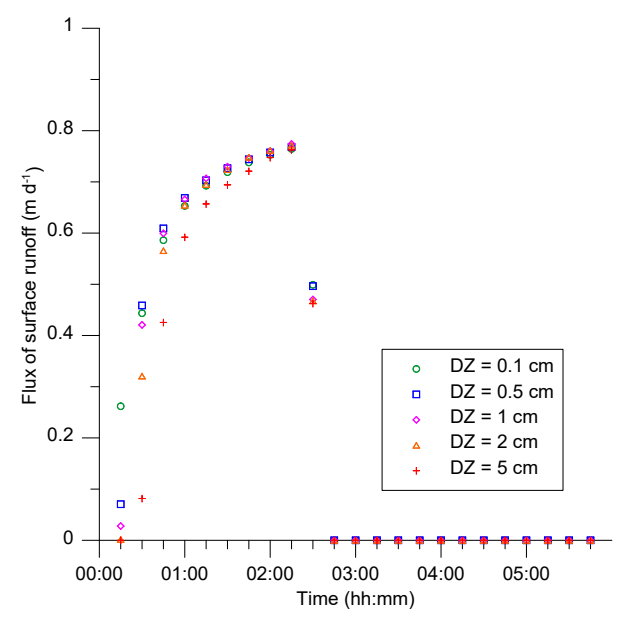

e)

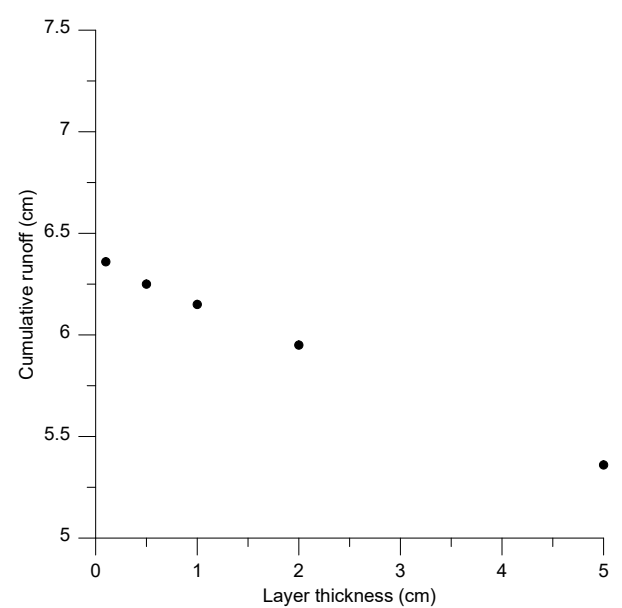

b)

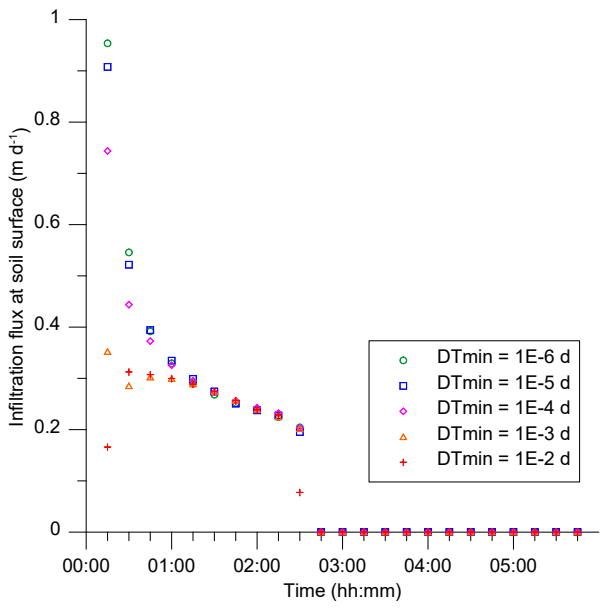

d)

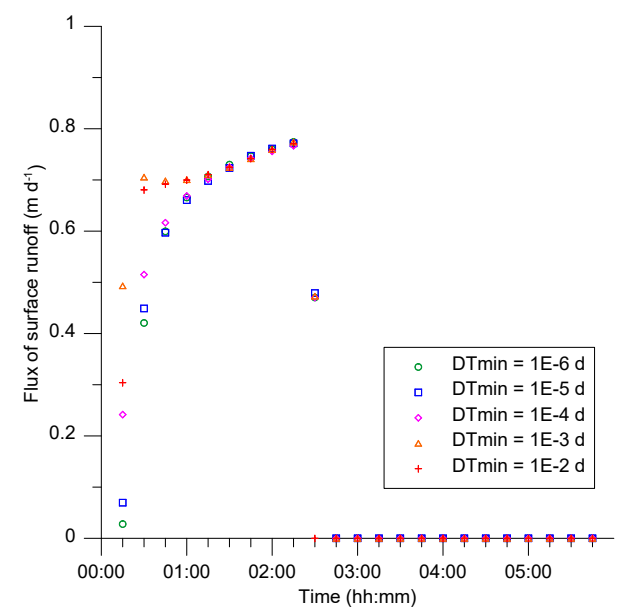

f)

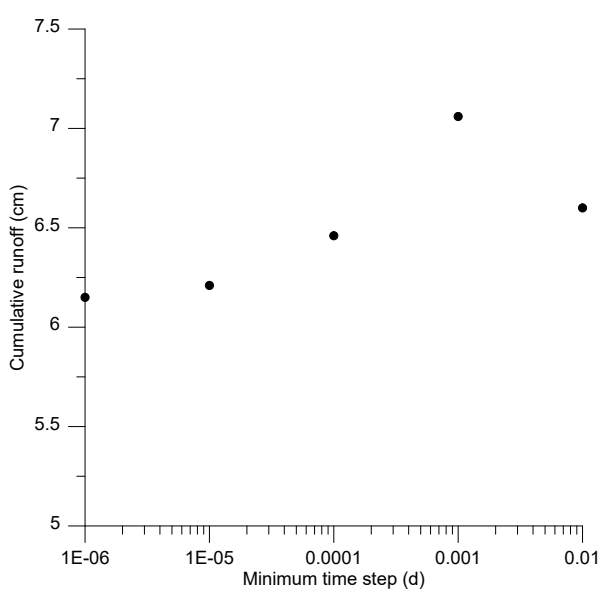

Figure 14. Time courses of infiltration flux and surface runoff flux as a function of spatial discretization ( $a$ and $c$, respectively) and as a function of minimal time step ( $b$ and $d$, respectively), and cumulative runoff as a function of e) layer thickness or $f$ ) minimum time step. Note that the $y$ scales do not start at zero. 
In addition, the sensitivity of the runoff equation in SWAP can also be analysed analytically. The runoff equation in SWAP is given by

$$
q_{\text {runoff }}=\left\{\begin{array}{cc}
0 & H \leq 0 \\
\frac{H_{\text {ref }}}{\gamma}\left(\frac{H}{H_{\text {ref }}}\right)^{\beta} & H>0
\end{array}\right.
$$

where $H$ is the height of the ponded water layer above the threshold, i.e., $H=h_{0}-h_{0, \text { threshold, }} H_{\text {ref }}$ is a reference value for $H$ with $H_{\text {ref }}$ by definition equal to $1 \mathrm{~cm}, \beta$ is a dimensionless shape parameter which according to Manning's theory equals 5/3 or approximately 2 (Hillel, 1980), and $\gamma$ is a resistance of water flow over the land surface (d). The presence of the (dummy) variable $H_{\text {ref }}{ }^{2}$ is there to avoid the dimension of $\gamma$ being a function of the value of $\beta$.

The sensitivity of this equation for changes (uncertainty) in the magnitude of the contributing parameters can be quantified as follows. The elasticity $(E)$ is defined as the relative change in function value $(f)$ divided by the relative change in parameter value $(p)$, given by

$$
E=\frac{\mathrm{d} f / f}{\mathrm{~d} p / p}=\frac{p}{f} \frac{\mathrm{d} f}{\mathrm{~d} p}
$$

A value of $E=+1$ means that $\mathrm{x} \%$ change in parameter $p$ results in $\mathrm{x} \%$ change in function value $f$; for $E$ $<1$ the sensitivity is low, whereas for $E>1$ the sensitivity is high. The elasticity for the runoff equation can be given analytically as follows. The sensitivity to changes in $H(>0)$ is given by

$$
E_{H}=\beta
$$

Since $\beta$ equals about $5 / 3$ to 2 , runoff is sensitive to changes in $H$, which, of course, changes during the simulation. The sensitivity to changes in $\gamma$ is given by

$$
E_{\gamma}=-1
$$

Irrespective of $H$ and $\beta$ runoff changes minus the same magnitude as $\gamma$; e.g. if the resistance increases by $50 \%$ runoff will decrease by $50 \%$. The sensitivity to changes in $\beta$ is given by (Figure 15)

$$
E_{\beta}=\beta \ln \left[\frac{H}{H_{\text {ref }}}\right]
$$

The sensitivity equals $\beta$ multiplied by the natural logarithm of $H$. For $H<H_{\text {ref }}(H<1 \mathrm{~cm})$ this means that runoff decreases with increasing $H$, and for $H>H_{\text {ref }}(H>1)$ this means that runoff increases with increasing $H$; for the special case $H=H_{\text {ref }}$ the sensitivity equals zero.

Since elasticities of 1 or more are present this means that the parameters $\beta$ and $\gamma$ need to be known well.

\footnotetext{
2 Note that in the SWAP manual (Kroes et al., 2017) no reference ponding height is used; however, the current and their equations are mathematically identical.
} 

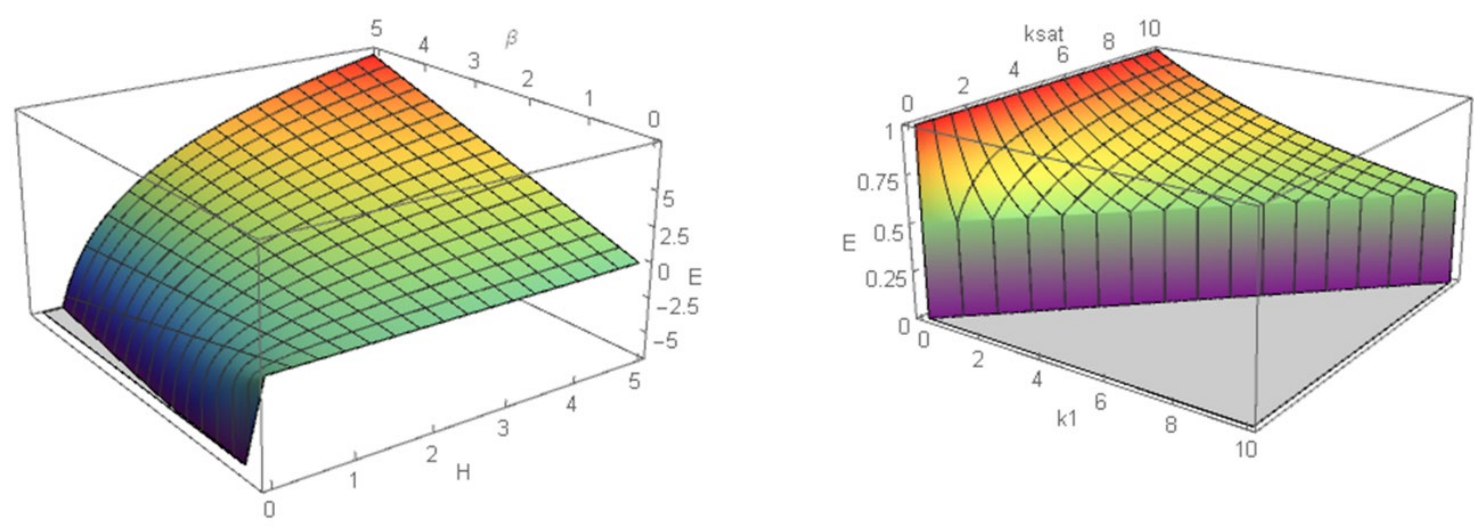

Figure 15. a) Elasticity (vertical axis) of the runoff equation as a function of parameter $\beta$ at different ponding heights $H$, and $b$ ) elasticity (vertical axis) of the maximum infiltration flux at the soil surface as a function of $K_{\text {sat }}$ at different values of $K_{1}$ of the top soil layer.

Since $H$ comprises the actual ponding height $\left(h_{0}\right)$ and the runoff threshold ponding height $\left(h_{0, \text { threshold }}\right)$

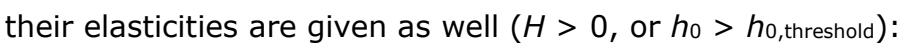

$$
E_{h_{0}}=\frac{h_{0}}{h_{0}-h_{0, \text { threshold }}} \beta
$$

and

$$
E_{h_{0, \text { threshold }}}=-\frac{h_{0, \text { threshold }}}{h_{0}-h_{0, \text { threshold }}} \beta
$$

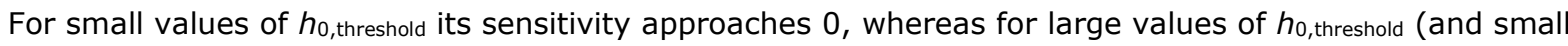

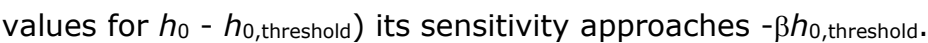

\subsection{Capillary rise}

Van Walsum and Veldhuizen (2011) considered a semi-dynamic case study with focus on the development of a steady-state capillary rise situation (their section 5.4.1). A soil profile (length 550) initially in hydrostatic equilibrium with groundwater level at $100 \mathrm{~cm}$ below soil surface is subject to constant evapotranspiration of $3 \mathrm{~mm} \mathrm{~d}^{-1}$. The grass crop has a constant rooting depth of $30 \mathrm{~cm}$. At 100 $\mathrm{cm}$ below soil surface a infiltration drain (resistance $50 \mathrm{~d}$ ) is present that acts as the source of water. A steady-state condition will develop in course of time. Four conditions differing in spatial discretization was studied by van Walsum and Veldhuizen (2011) which was used here too (Table 7). The main focus is on the dynamics that occurs between the infiltrating drain depth (100 cm below soil surface) and the soil surface. Note that for the upper layers (rooting zone) the differences between the four cases is small, and the major differences are seen at depth $50-150 \mathrm{~cm}$.

Figure 16 shows the development of the steady-state upward water flux density (capillary rise) at depths 30,50 and $100 \mathrm{~cm}$ and the development of the pressure head at the soil surface (first layer). Table 8 shows the differences in at the end of the simulation period (365 d). According to the coarser discretization (Case 4) the capillary rise was highest and actual transpiration was equal to potential transpiration. It required the highest input of water from the infiltrating drain, resulted in the lowest groundwater level. 
Table 7. Spatial discretization scheme for four cases used in the capillary rise test.

\begin{tabular}{|c|c|c|c|c|}
\hline Soil depth & $\begin{array}{l}\text { Case } 1 \\
(1 \mathrm{~cm})\end{array}$ & $\begin{array}{l}\text { Case } 2 \\
(2.5 \mathrm{~cm})\end{array}$ & $\begin{array}{l}\text { Case } 3 \\
(5 \mathrm{~cm})\end{array}$ & $\begin{array}{l}\text { Case } 4 \\
\text { (variable) }\end{array}$ \\
\hline $0-5$ & 1 & 1 & 1 & 1 \\
\hline $5-35$ & 1 & 2.5 & 2.5 & 2.5 \\
\hline $35-50$ & 1 & 2.5 & 5 & 5 \\
\hline $50-90$ & 1 & 2.5 & 5 & 10 \\
\hline $90-150$ & 1 & 2.5 & 5 & 10 \\
\hline $150-550$ & 1 & $\begin{array}{l}10(150-240) \\
20(240-300) \\
50(300-550)\end{array}$ & $\begin{array}{l}10(150-240) \\
20(240-300) \\
50(300-550)\end{array}$ & $\begin{array}{l}10(150-200) \\
20(200-300) \\
40(300-540)\end{array}$ \\
\hline
\end{tabular}

The case with the fine discretization (Case 1) resulted in the lowest actual transpiration (5.2\% less that potential transpiration), the lowest input of water from the infiltrating drain (13.7\% less than for Case 4$)$, and the highest groundwater level. The steady-state capillary rise equals between 2 and $2.5 \mathrm{~mm} \mathrm{~d}^{-1}$, which is less than the potential evapotranspiration rate of $3 \mathrm{~mm} \mathrm{~d}^{-1}$. This difference is partly due to differences in actual transpiration (Table 8) and partly due to a great reduction in evaporation at the soil surface $\left(E_{\mathrm{act}}=24.3 \mathrm{~mm}, E_{\mathrm{pot}}=202 \mathrm{~mm}\right.$; for all cases). The difference in position of the groundwater level are small. Great differences, however, are seen at the soil surface. Cases 1 and 2 show extremely drying out of the top layer compared to Case 4.

a)

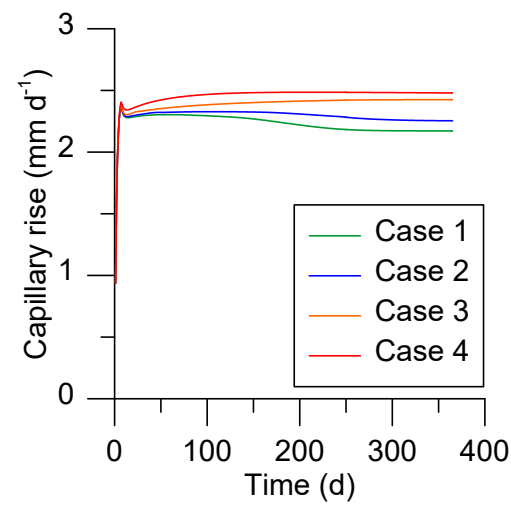

c)

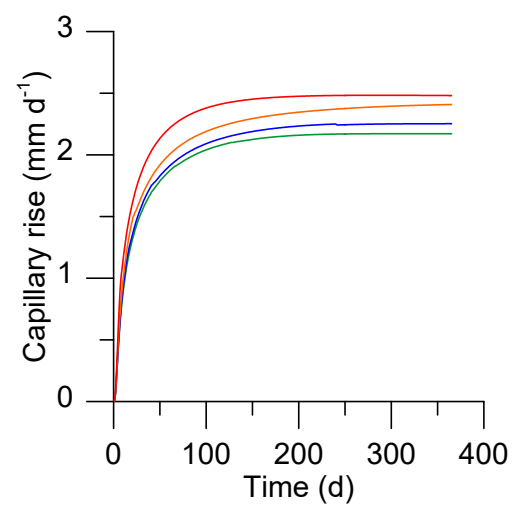

b)

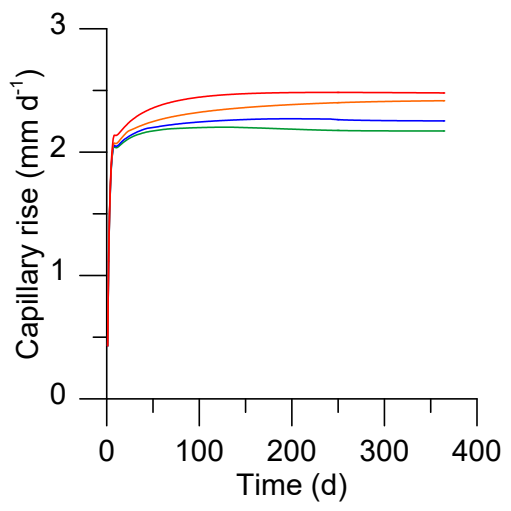

d)

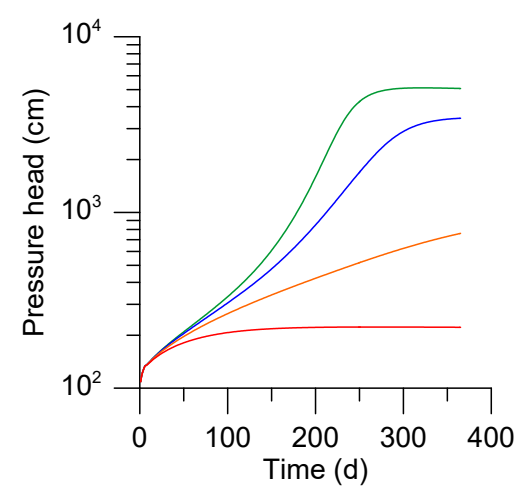

Figure 16. a-c) Development in time of the upward water flux density (capillary rise) at depths a) 30 $\mathrm{cm}$, b) $50 \mathrm{~cm}$ and c) $100 \mathrm{~cm}$ for the four cases; d) presents the time course of the pressure head in the top layer (note the logarithmic y-scale). 
Table 8. Some selected cumulative outcome for the four cases for the capillary rise test.

\begin{tabular}{|c|c|c|c|}
\hline & $\begin{array}{l}\text { Actual transpiration } \\
(\mathrm{mm})\end{array}$ & $\begin{array}{l}\text { Groundwater level } \\
\text { (cm below soil surface) }\end{array}$ & $\begin{array}{l}\text { Drain inffltration } \\
(\mathrm{mm})\end{array}$ \\
\hline Case 1 & 846.6 & 110.9 & 729.8 \\
\hline Case 2 & 867.5 & 111.1 & 753.3 \\
\hline Case 3 & 891.8 & 112.0 & 795.0 \\
\hline Case 4 & 893.0 (= potential) & 112.4 & 845.6 \\
\hline
\end{tabular}

In these calculations normal arithmetic averaging of $K$ at the layer interfaces was used. When using weighted geometric averaging for Cases 1 and 4 this resulted in very small differences in steady-state capillary rise at depth $30 \mathrm{~cm}(<1 \%)$. For Case 4 a simulation with $K$ implicitly included in the numerical solution of the Richards equation resulted in negligible differences.

Recently Kroes et al. (2018) analysed the impact of capillary rise and recirculation of percolation water below grassland, maize and potatoes in Dutch soils. They concluded that soil water and crop growth modelling should consider both capillary rise from groundwater and recirculation of percolation water as this improves the accuracy of yield simulations. Neglecting these processes implies neglecting yield reductions for grassland, maize and potatoes of respectively 26,3 and $14 \%$ or respectively about 3.7 , 0.3 and 1.5 t dry matter per hectare and overestimates of groundwater recharge of $17 \%$ for grassland and $46 \%$ for potatoes, or 63 and $34 \mathrm{~mm} \mathrm{yr}^{-1}$, respectively.

\subsection{Case study Watervision Agriculture}

For the project Watervision Agriculture (Dutch: Waterwijzer Landbouw ${ }^{3}$ ) the following sensitivity analysis was performed (own study, unpublished data). Estimation of actual evapotranspiration and actual crop yield using SWAP-WOFOST is complex. A large number of variables need to be known in order to obtain realistic output. A regression-based sensitivity analysis was performed to identify the uncertainty contribution of input variables and parameters (i.e., those determining $E T, \mathrm{CO}_{2}$, phenology and stress: nine in total ${ }^{4}$ ) in relation to specific model output (typically $E T, \theta$ and dry matter production). A MonteCarlo type analysis was performed assuming parameter probability density functions.

Average annual evapotranspiration was $220 \mathrm{~mm}$ with a $95 \%$ confidence interval between 180 and 260 $\mathrm{mm}$ (Figure 17a). The actual yield was $11250 \mathrm{~kg} \mathrm{ha}^{-1}$ with a $95 \%$ confidence interval between 6000 and $16000 \mathrm{~kg} \mathrm{ha}^{-1}$ (Figure 17b). By linear regression the total percentage of variation accounted for was $85 \%$ for ET and $90 \%$ for dry matter production. For both ET and yield the parameter EFF contributed the most to the percentage variance accounted for (Figure 17c,d). Based on a day-to-day application of this method revealed that the sensitivity for the studied parameters differs throughout the season (Figure 18).

\footnotetext{
${ }^{3}$ http://waterwijzer.stowa.nl/Achtergronden/Waterwijzer Landbouw algemeen.aspx

${ }^{4}$ AMAXTB [max CO2 assimilation rate], EFF [light use efficiency], CFBS [coefficient to convert potential evapotranspiration into potential evaporation], $\mathrm{CH}$ [crop height], CROPSTART [starting date of crop growth] KDIF [extinction coefficient for diffuse visible light], RELNI [RELMF; management factor to account for other forms of stress], SLATB [specific leaf are], TSUMEA [temperature sum from emergence to anthesis]
} 
a)

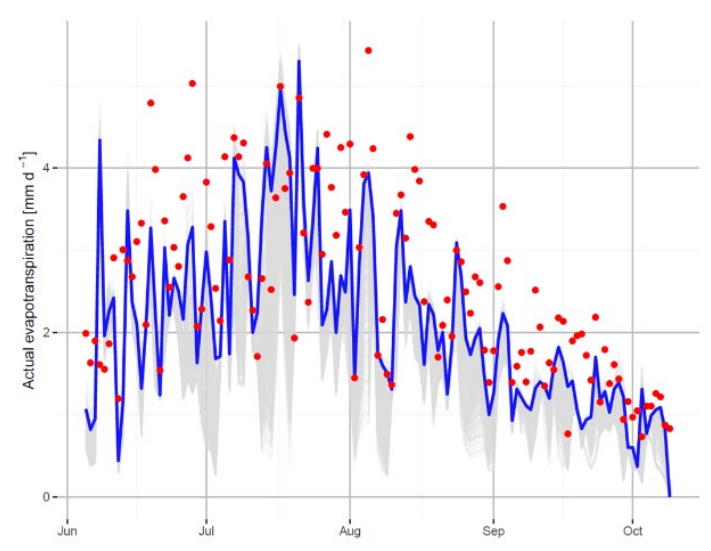

c)

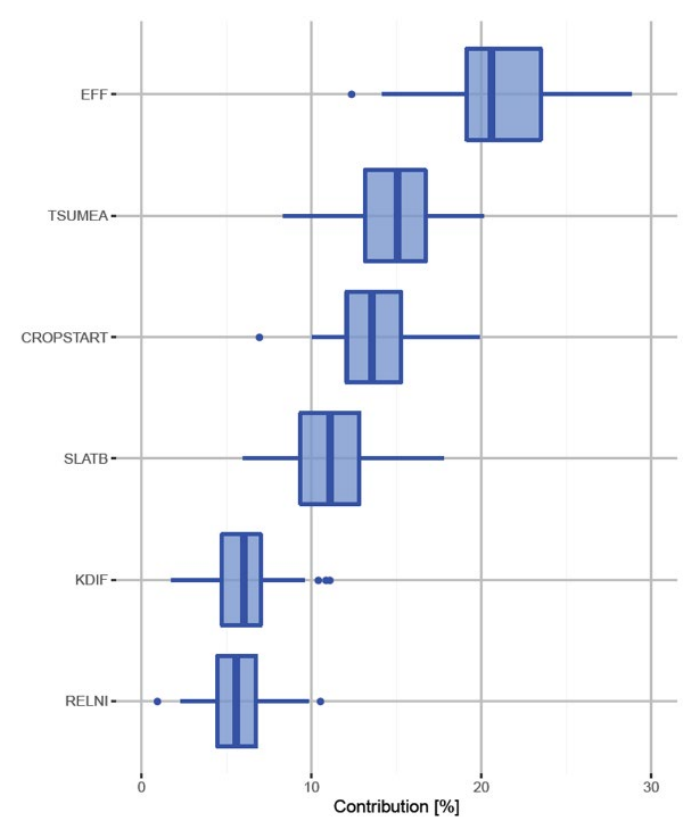

b)

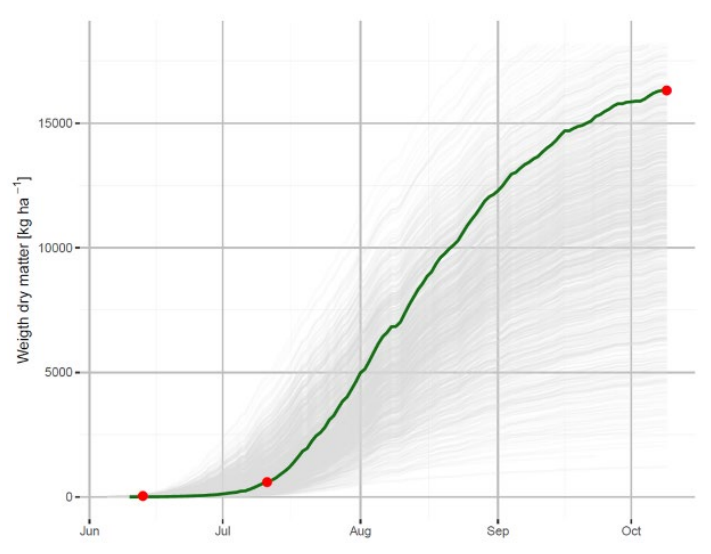

d)

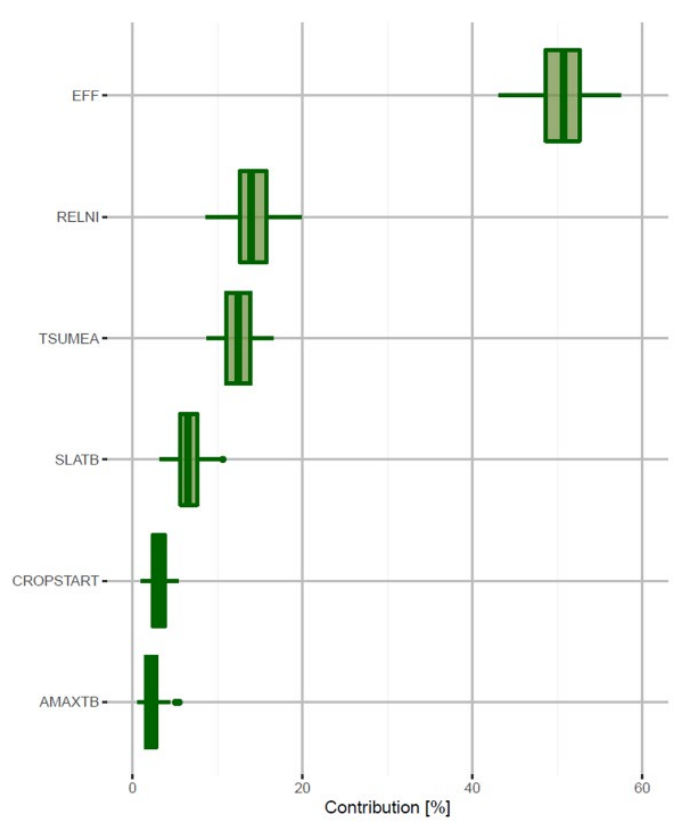

Figure 17. Uncertainty analysis of a) actual evapotranspiration and b) actual crop yield in time (in grey modelled realisations, in a) blue and b) green the best modelled realisation and in red the observations), and confidence limits of contribution to the explained variance for c) actual evapotranspiration and d) actual crop yield for the six most sensitive parameters. 


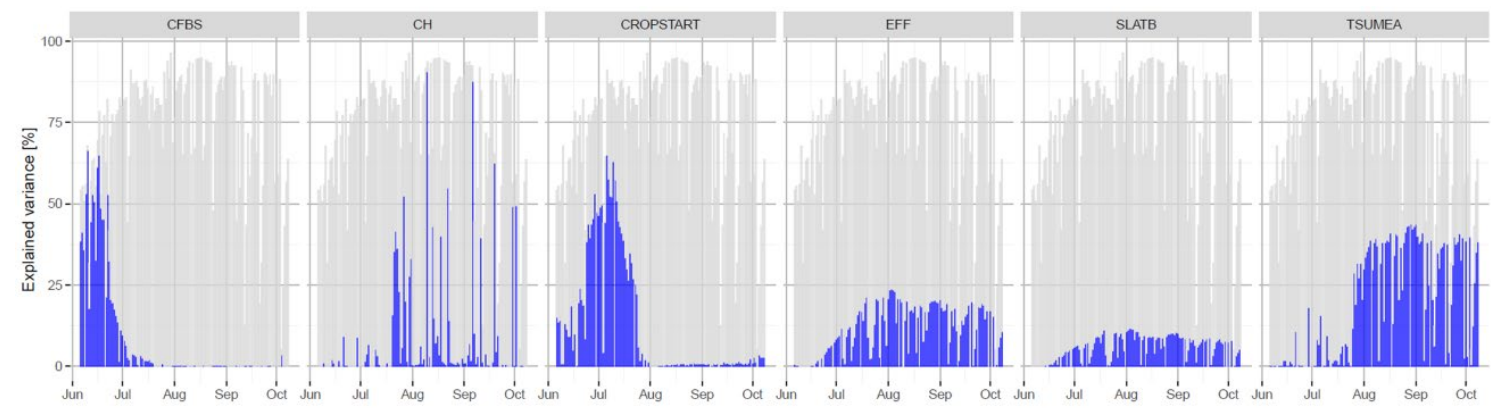

Figure 18. Explained variance (grey) in time for actual evapotranspiration with contribution of the most sensitive parameters (blue).

\subsection{SWAP sensitivity analyses in literature}

In several studies published in the literature sensitivity (or uncertainty) analyses have been reported using the SWAP model. In this chapter some selected studies will be briefly described, and some of the conclusions reported by these authors will be given. For details, the reader is referred to the citations.

\subsubsection{Groenendijk et al. (2014)}

In the GENESIS ${ }^{5}$ project (EU FP7) measured nitrate leaching in a lysimeter was used to perform model comparison between several simulation models, with SWAP being one of the models. Before the actual calibration and validation simulations were done, it was decided to perform a sensitivity analysis (Groenendijk et al., 2014). Based on the soil profile description, the depths at which sensors were installed, the cropping cycles, and measured pressure heads at the bottom of the lysimeter, the SWAP model was parameterized. The major unknowns were the physical properties of the soil layers and some crop growth parameters. A one-at-a-time sensitivity analysis (using the SENSAN module of PEST (Doherty, 2005)) was performed for the six Mualem-van Genuchten parameters of the five soil layers, two parameters determining soil evaporation and five parameters determining the effects of frost and snow, the maximum rooting depth, and 14 crop parameters for eight crops (in total 150 parameters). Based on a best initial guess for each of these parameters, they were changed by $+10 \%$ and by $-10 \%$. The objective function was composed of the sum of squared differences between 1461 observed and predicted values of daily seepage water amounts (weight 1.0), and daily water content data at depths $0.35,0.6,0.9$ and $1.8 \mathrm{~m}$ (weight 10.0). For that both the Pearson r ranking, RMSE (root mean squared error) ranking and bias ranking were calculated, and finally these rankings were averaged. Figure 19 shows the obtained outcome of this analysis. From that it was concluded that for later calibration the focus needed to be on the Mualem - Van Genuchten parameters $\theta_{s}, n$, and $K_{s}$ for all five soil layers, one soil evaporation reduction parameter (COFRED), one snowmelt parameter (SNOWCOEF), and for each crop the maximum LAI at harvest. For the two sensitive crop parameters albedo and crop resistance it was decided that default known parameters from the literature would suffice.

5

http://www.bioforsk.no/ikbViewer/page/prosjekt/hovedtema?p dimension id=16858\&p menu id=16904\&p su $\underline{b}$ id $=16859 \& p \operatorname{dim} 2=16860$ 


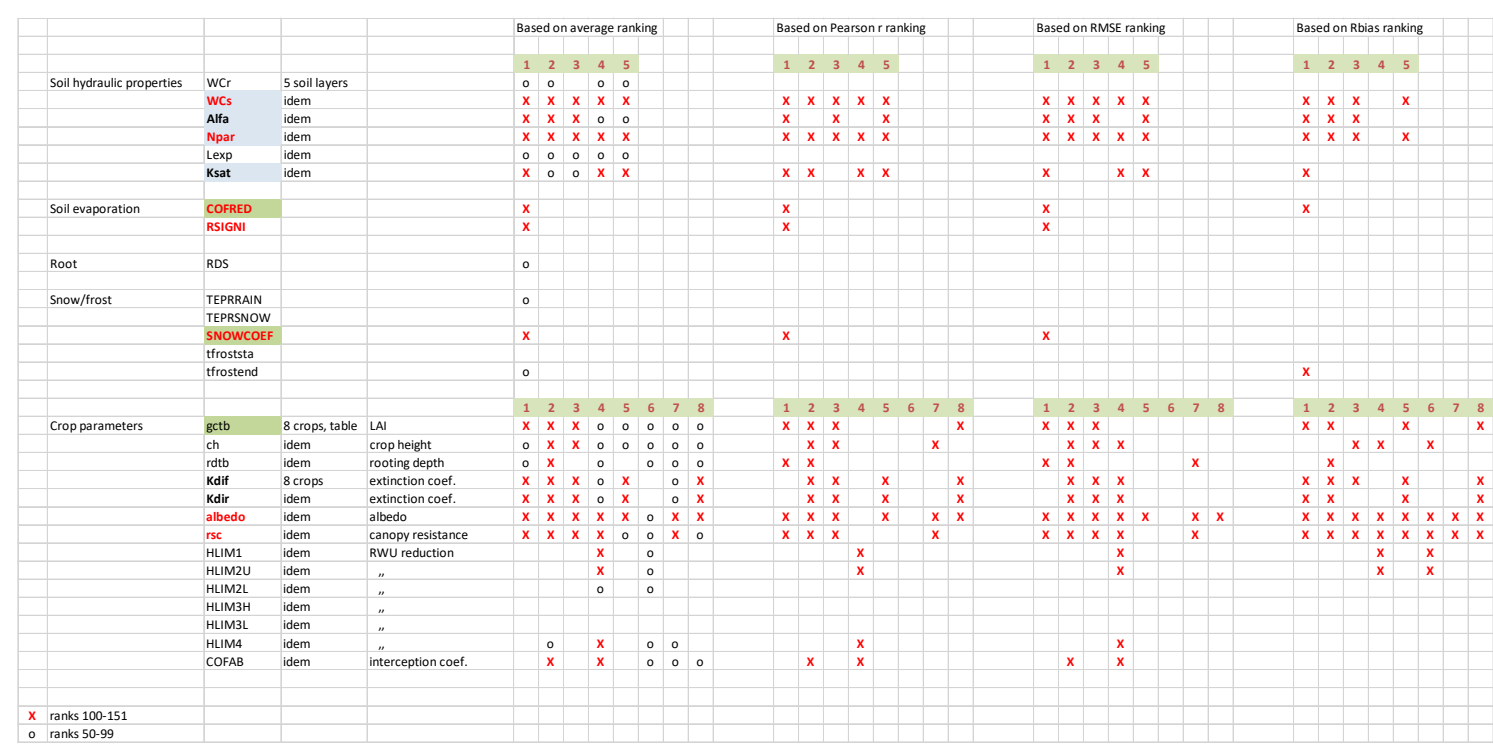

Figure 19. Summary of the outcome of the combined ranking of sensitivities of the 14 soil parameters (the first six for each of the five soil layers considered) and 14 crop parameters (for each of the eight crops considered) in the one-at-a-time sensitivity analysis in the GENSEIS lysimeter study (own data underlying the data presented in Groenendijk et al., 2014). A red cross indicates that the parameter was classified in the top third of the ranked sensitivities, an black open circle indicates that there was moderate sensitivity (classified in the range one-third to two-third ranking), and no indication means low sensitivity (lowest one-third in the ranking).

\subsubsection{Droogers et al. (2008)}

Simulation models are, by definition, approximations of reality. When studying the effects of, e.g., climate change based on model predictions, one could argue that observed effects are due to model errors. To evaluate the impact of model inaccuracy on impact assessment of climate change Droogers et al. (2008) altered the calibrated model to reflect the most common parameter uncertainties. A $10 \%$ change was applied to the following parameters: the Mualem-van Genuchten parameters $\alpha, n$ and $K_{\text {sat, }}$ the average value and amplitude of the bottom water flux density, and the Feddes transpiration reduction parameters $h_{3}$ and $h_{4}$. The major output variables considered were (averaged over 30 years): actual evapotranspiration $\left(E T_{\text {act }}\right)$, water shortage $\left(E T_{\text {short }}=E T_{\text {pot }}-E T_{\text {act }}\right)$, groundwater level $\left(G W L_{\text {avg }}\right)$, number of days when GWL was within $50 \mathrm{~cm}$ (GWLwet) and below $170 \mathrm{~cm}$ (GWLdry), crop yield (Yield), and number of years where crop yield was less than $80 \%$ of potential (Crop Fail). To express the impact of model inaccuracy versus the impact of the scenario itself, they introduced the Model-Scenario-Ratio (MSR) measure for their evaluation. "The value of MSR indicates to what extent the impact of a scenario contributes to the final findings compared to model inaccuracy. An MSR value of 1 indicates that the model inaccuracy doesn't play a role and results are a function of the scenario only. An MSR value of 0 indicates that the response of the impact assessment originates for $50 \%$ from the changing climate scenario, and $50 \%$ from an inherent model uncertainty. MSR values lower than zero indicate that responses are dominated by model inaccuracy rather than by the scenario evaluated."

Their analysis focussed on the impact of climate scenarios $W$ and $W+$ compared to reference climate. Their results are summarized in Figure 20.

They concluded that:

- for the two climate scenarios an increase in water shortage, more extremes in wet and dry periods, and a small reduction in agriculture production can be expected 
- $\quad$ for the W scenario the MSR analysis indicated that model inaccuracy was not relevant for most indicators

- $\quad$ for the $W+$ scenario (enhanced drought conditions) model inaccuracy plays a role for some indicators. However, $>90 \%$ of the assessed impact could still be attributed to the scenario itself and not to model inaccuracy.

\begin{tabular}{lcrrrrrrr}
\hline & & & \multicolumn{4}{c}{ Difference from reference } \\
\hline & & Reference & $\mathrm{W}$ & $\mathrm{W}+$ & $\mathrm{W}$ & $\mathrm{W}+$ & $\mathrm{W}(\%)$ & $\mathrm{W}+(\%)$ \\
ETact & $(\mathrm{mm} / \mathrm{y})$ & 550 & 577 & 573 & 27 & 23 & 5 & 4 \\
ETshort & $(\mathrm{mm} / \mathrm{y})$ & 34 & 46 & 93 & 11 & 58 & 33 & 169 \\
GWLavg & $(\mathrm{cm})$ & -116 & -116 & -125 & 0 & -10 & 0 & -8 \\
GWLwet & $(\mathrm{d} / 30 \mathrm{y})$ & 43 & 60 & 57 & 17 & 14 & 40 & 33 \\
GWLdry & $(\mathrm{d} / 30 \mathrm{y})$ & 1136 & 1150 & 2341 & 14 & 1205 & 1 & 106 \\
Yield & $(€ / \mathrm{ha})$ & 1299 & 1283 & 1199 & -16 & -100 & -1 & -8 \\
Crop Fail & $(\mathrm{y} / 30 \mathrm{y})$ & 1 & 1 & 2 & 0 & 1 & 0 & 100 \\
\hline
\end{tabular}

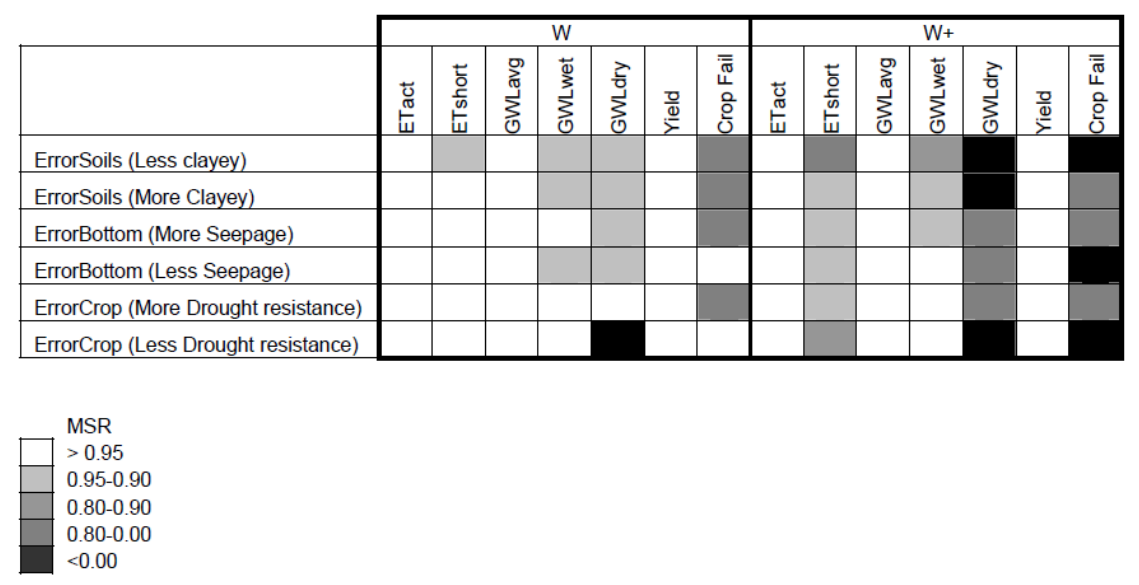

Figure 20. (top) Differences in response variables for climate scenario simulation $W$ and $W+$ compared to the reference situation and (bottom) the Model-Scenario-Ratio (MSR) per response variable per scenario for 6 model perturbations (source: Droogers et al., 2008). Less Clayey: $n+10 \%$, $\alpha-10 \%, K_{\text {sat }}+10 \%$; More Clayey: $n-10 \%, \alpha+10 \%, K_{\text {sat }}-10 \%$; More Seepage: $+10 \%$ in seepage dynamics parameters; Less Seepage $-10 \%$ in seepage dynamics parameters; More Drought Resistance: $h_{3, \mathrm{lim}}+10 \%, h_{4, \mathrm{lim}}+10 \%$; More Drought Resistance: $h_{3, \mathrm{lim}}-10 \%, h_{4, \mathrm{lim}}-10 \%$.

\subsubsection{Stahn et al. (2017)}

Stahn et al. (2017) performed a global Sobol variance-based sensitivity analysis for SWAP (version 3.2.36). Details of the method employed can be found in the paper. In total 15 parameters were considered: five parameters for the Mualem-van Genuchten soil hydraulic properties $\left(\theta_{s}, n, \alpha, \lambda, K_{s}\right)$, three rooting distribution parameters (srd [shape parameter for exponential root distribution], sr [shape parameter for logistic root depth increase, $R_{\max }$ [maximum rooting depth]), three transpiration reduction parameters of the Feddes function ( $h_{3, \text { high }}, h_{3, \text { low }}, h_{4}$; determining drought stress), three crop coefficients $\left(K_{\mathrm{c}, \text { ini }}, K_{\mathrm{c}, \text { mid }}, K_{\mathrm{c}, \text { end }}\right)$ and LAI. The sensitivity was performed with focus on simulated volumetric water contents and soil pressure heads (compared to measurements at depths 30 and $60 \mathrm{~cm}$ ). High sensitivities were observed for parameters $s r d, K_{\mathrm{c}, \text { mid }}, n, \theta_{\mathrm{s}}$ and $K_{\mathrm{s}}$ (in that order) when considering their effects on volumetric water content; for pressure head these were $\theta_{s}, K_{s}, n$ and $K_{\mathrm{c} \text {, mid }}$ (in that order) (Figure 21). The most sensitive parameters were later optimized using a calibration procedure. For the none-sensitive parameters the authors stated: "It cannot be expected that information on the overall 
insensitive parameters ( $h_{3, \text { high, }} h_{3, \text { low }} h_{4}, s r$ and $\left.k_{c, \text { end }}\right)$ would be provided by the observational data. Therefore, these parameters were excluded from optimisation by fixing them to experience values."

The authors summarized and concluded with (some quotes):

- $\quad$ Mixed cropping was effectively represented in the model [SWAP] structure.

- These results demonstrate how complex and variable the relationship between parameters and model outputs can be in simulation models such as SWAP and underline the necessity of conducting a global sensitivity analysis to detect such patterns.

- $\quad$ These findings underline once again the need of considering multiple data types in parameter optimisation in order to constrain the resulting solutions to describe different model outputs simultaneously well.

- The results showed that most of the parameters are well identified, independent of the level of parameter interaction. However, interactions seem to be relevant for parameter identifiability.
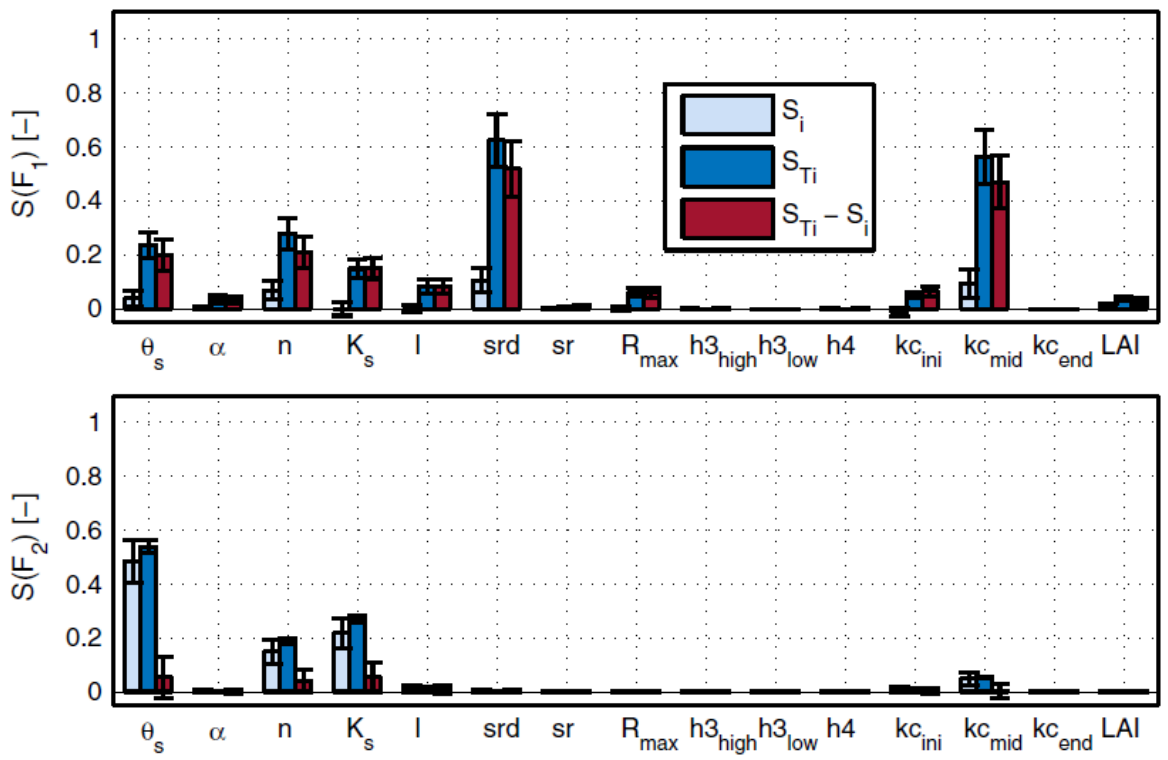

Figure 21. Estimations of first- $\left(S_{i}\right)$ and total-order $\left(S T_{i}\right)$ indices of the Sobol sensitivity method obtained for fitting criteria $F_{1}$ (volumetric water content; top panel) and F2 (pressure head; bottom panel). The interacting effect of each parameter $i$ is given by the difference between $S_{i}$ and $S_{i}$. The error bars represent the confidence intervals of the sensitivity indices estimated with bootstrapping (source: Stahn et al., 2017).

\subsubsection{Wanders et al. (2012)}

Wanders et al. (2012) performed a Monte-Carlo-type sensitivity analysis using SWAP to determine the $95 \%$ confidence interval of predicted soil moisture at $5 \mathrm{~cm}$ depth and compared this with measured soil moisture contents for a test site in central Spain. The following parameters were used in their sensitivity analysis: the Mualem-van Genuchten parameters $\theta_{r}, \theta_{s}, \alpha, n, K$, the meteorological input variables precipitation and evapotranspiration, and the crop leaf are index. No detailed information on the probability density functions for these parameters were provided. For the year 2010 a good agreement between modelled and observed water contents (with a slight positive bias equal to $0.01 \mathrm{~m}^{3} \mathrm{~m}^{-3}$ ), with a narrow 95\% confidence interval around the modelled results (Figure 22a). For the months May and June the model slightly over-estimated the observations, which according to the authors was "probably caused by an underestimation of evapotranspiration." They also presented this comparison in a so-called QQ-plot (Figure 22b). The predictive QQ-plot is a measure to check whether the obtained Monte Carlo 
simulation results in a probability density function (PDF) that corresponds to the PDF of the model prediction errors. "The predictive QQ-plot ... shows that the modeled soil moisture is within the $95 \%$ confidence interval of the Kolmogorov-Smirnov test (KS-test). The bias of $0.01 \mathrm{~m}^{3} \mathrm{~m}^{-3} \ldots$ was also found in the predictive QQ-plot. The SWAP model slightly overestimates the amount of low soil moisture values compared to the observations as seen from a small deviation below $0.2 \mathrm{~m}^{3} \mathrm{~m}^{-3}$ soil moisture content. This deviation is however not significant as shown by the KS-test."

This study does not provide quantitative data on which parameters are more sensitive and which others are less sensitive. Instead, it provides more insight in the uncertainty of model predictions for given uncertainty of several model parameters.

a)

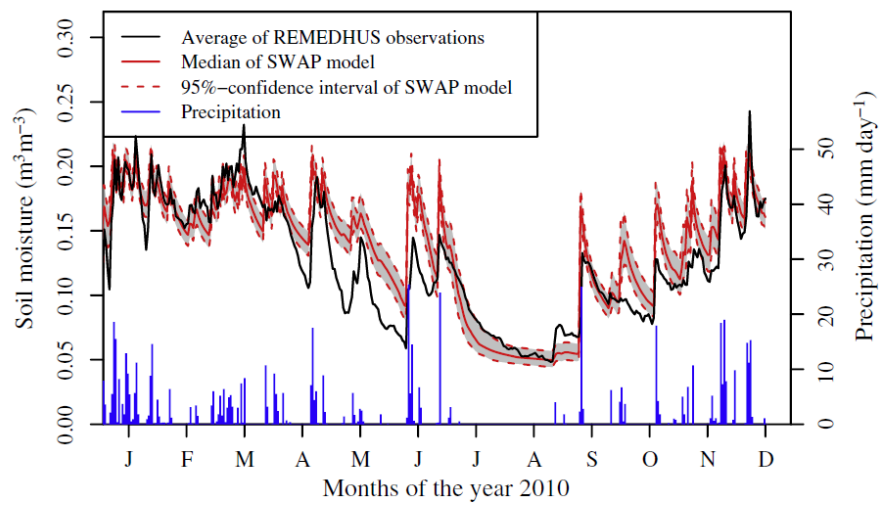

b)

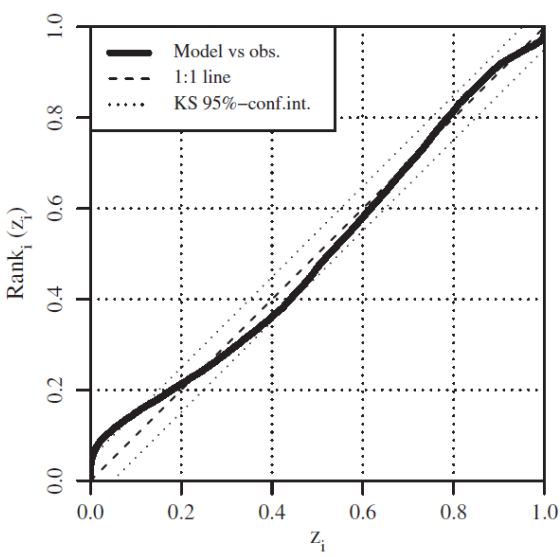

Figure 22. a) Comparison between the average SWAP modelled soil moisture and the average of the in-situ observations (the confidence interval is due to a sensitivity analysis of varying serval parameters), and $b$ ) the predictive QQ-plot for validation of the observations against the SWAP model predictions for the period 2006-2010; in b) the 95\% confidence interval of the Kolmogorov-Smirnov (KS) test and the 1:1 line are given as well (source: Wanders et al., 2012).

\subsection{The SWAP rerun option}

In order to facility the user in performing a sensitivity analysis SWAP has been extended with a so-called rerun option. With a single SWAP execution it is then possible to make changes in input variable and store the outcome in different output files. Afterwards the user can then analyse the changes in the desired output variables.

Reruns are activated once in the working directory the file reruns. dat is present. At first SWAP uses the input information of the main input files (.swp and others referred to) and after completion of the simulation reruns are done for the same situation except for the new values as stated in the reruns.dat file. If the name of the output file is changed for each rerun, the user can afterwards compare the different output files for the situations considered.

For example, suppose we want to study the impact of the different ways the $K$-averaging can be performed. There are six options for K-averaging. We start with indicating the first option in the main .swp file, including a unique name for the output file (OUTFIL). Then in the reruns.dat file we add the information for the remaining five cases by supplying for each case a new unique name of the output file and the new value for SWkmean (see Text Box below). After SWAP is run the user will find six output files with the corresponding names and the differences can be analysed and plotted. 
There is no restriction on the number of variables that can be changed. However, it is obligatory that for each set of variables per rerun the sequence of occurrence of the variable names must be the same. For example, if the two variables for rerun 3 are interchanged this would cause an error.

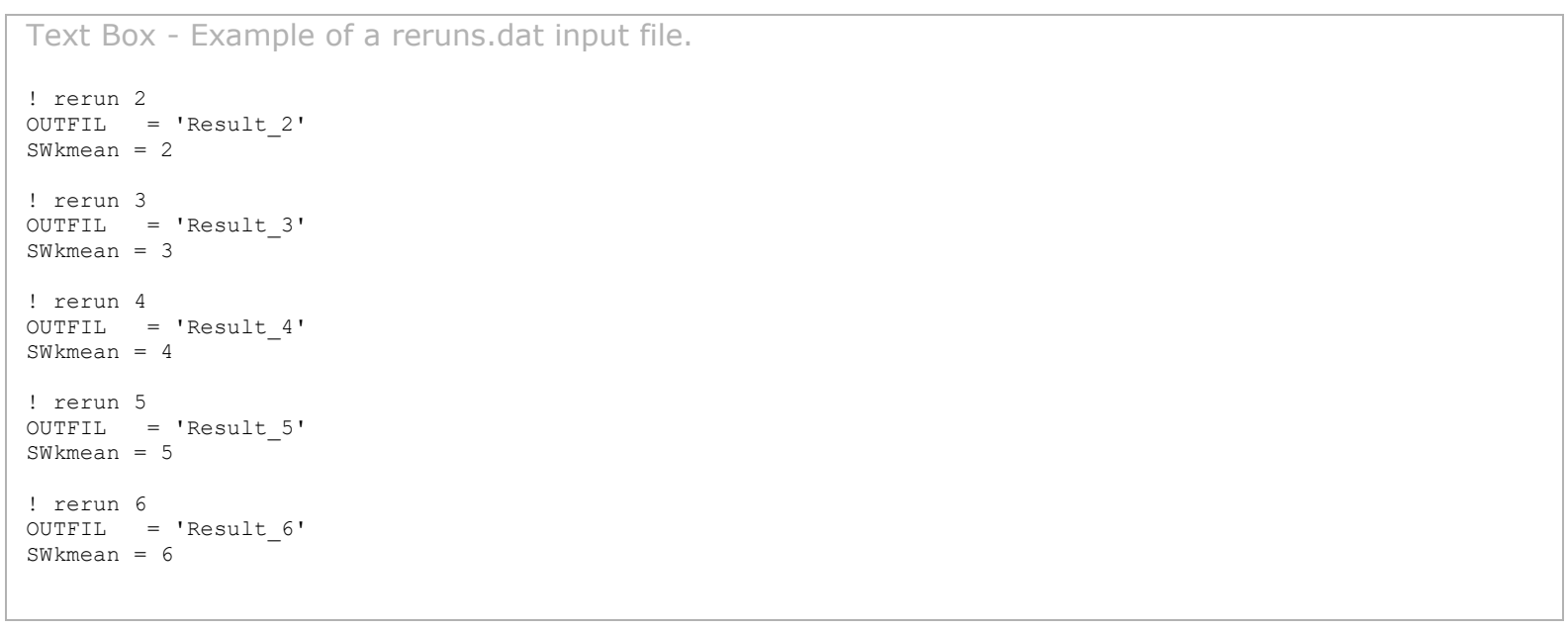

\subsection{Resume}

The analysis presented in this chapter is not meant to provide a universal sensitivity analysis of the SWAP-WOFOST model. It provides some insight in the model's sensitivity for a few case studies. The following general remarks are given:

1) It should be a good modelling practice to perform a sensitivity analysis at the start of a modelling project. As each project may have its own focus, so may be the sensitivity analysis different from study to study.

2) The heart of the SWAP model is formed by the numerical solution of the (non-linear) partial differential equations describing water movement and solute transport. Since it generally known that solving these equation numerically are dependent on the chosen spatial and temporal discretization, one should consider these as important.

3) There is no unique way to perform a sensitivity analysis. One can choose from screening methods (often used for models with a large number of input variables; e.g. the one-at-a-time method, several factorial methods, Cotter's method), local sensitivity analysis (often based on analytical partial derivatives; not always possible), and global sensitivity analysis (e.g. MonteCarlo analysis, response surface methodology, Fourier amplitude sensitivity test). Chapters 4.7.1 and 4.7.2 provided an example of the one-at-a-time screening method, and Chapters 4.6 and 4.7.3 provided examples of global sensitivity analyses.

4) Water movement in porous media is highly determined by the non-linear soil physical hydraulic properties. Therefore it is likely that SWAP is sensitive to the parameters that determine these properties (see Chapter 4.7.1, Chapter 4.7.3).

5) Crop production is determined by the environmental driving variables (radiation, temperature, $\mathrm{CO}_{2}$ ), but is also determined by transpiration. Transpiration is determined by the availability of water in the root zone. Therefore, crop growth is dependent on parameters that drive these processes (see example in Chapters 4.6, 4.7.2 and 4.7.3). 


\section{Calibration}

The main core of SWAP, as stated before, consists of the solution of the governing flow equation for water movement in soils. The solution is determined by initial and boundary conditions, as well as by soil properties. All the conditions and properties need to be supplied by the user; those are not hard-coded in SWAP. Only universal constants or scientifically accepted parameter values have been coded hard in the source code. Technical calibration of internal parameters is not operational (this will only occur when new routines will be implemented). In summary, technical calibration is not implemented, because:

- $\quad$ state-of-the-art theory (see manual by Kroes et al., 2017);

- $\quad$ state-of-the-art solutions; e.g. both the soil water movement and soil temperature problems are posted as matrix-vector problems, and for one-dimensional situations these matrix-vector problems can be solved mathematically by using the well-known tri-diagonal solver (see tridag.f90; theory described in e.g. Press et al., 1986);

- $\quad$ non-trivial code (e.g. mass balance computations: change in storage = input-output);

- universal constants should not be calibrated (e.g. the von Karman constant $(=0.41)$ as used in the Penman-Monteith subroutine PenMon);

- $\quad$ some constants have been imposed constant in code based on literature (e.g. thermal properties of soil components; see parameter definitions in subroutine DeVries (temperature.f90) and Table 9.1 of the manual by Kroes et al., 2017).

Most model variables are model input variables, which allows the user to calibrate, validate, verify or check for plausibility whether the outcome matches observations.

Several papers have been published in the scientific literature where SWAP was compared against other models, against analytical solutions and/or against available data: for example, Eitzinger et al., (2004), vandenBorght et al. (2005; see also comment by Groenendijk et al., 2006), Bonfante et al. (2010), Hack-ten Broeke et al. (2013), Groenendijk et al. (2014), Kroes et al. (2015). 


\section{Technical documentation}

The theory of the SWAP-WOFOT model, including the simple N-module, and the accompanying description of user instructions for providing the input have been described in detail in Kroes et al. (2017) and Groenendijk et al. (2017). In the current document some additional background information has been provided as well as examples of verification, validation and sensitivity studies.

All this information is publicly available on the website swap.wur.nl. This includes the source code and executable of SWAP, which can be freely used (the software is distributed under the terms of the GNU GENERAL PUBLIC LICENSE Version 2, June 1991).

What is not publicly documented is a technical documentation ${ }^{6}$ regarding the development, maintenance, version control and internal testing of the source code. For this purpose an internal technical documentation has been prepared, which is a pre-requisite for the Wageningen Environmental Research Status A qualification.

\footnotetext{
${ }^{6}$ Heinen, M., M. Mulder, J. Kroes. 2020. Technical document SWAP version 4. Internal document, Wageningen
} Environmental Research. 


\section{References}

Basha, H.A. 1999. Multidimensional linearized nonsteady infiltration with prescribed boundary conditions at the soil surface. Water Resources Research 35: 75-83.

Beven, K.J., D.E. Henderson, and A.D. Reeves. 1993. Dispersion Parameters for Undisturbed Partially Saturated Soil. Journal of Hydrology 143: 19-43.

Boogaard, H.L., A.J.W. De Wit, J.A. te Roller, C.A. Van Diepen, 2014. WOFOST CONTROL CENTRE 2.1; User's guide for the WOFOST CONTROL CENTRE 2.1 and the crop growth simulation model WOFOST 7.1.7. Wageningen (Netherlands), Alterra, Wageningen University \& Research Centre.

De Wit, A., H. Boogaard, D. Fumagalli, S. Janssen, R. Knapen, D. van Kraalingen, I. Supit, R. van der Wijngaart, K. van Diepen, 2019. 25 years of the WOFOST cropping systems model. Agricultural Systems 168 , p. $154-167$

Doherty J. 2005. PEST Model-independent parameter estimation user manual: 5th edition. Watermark Numerical Computing.

Droogers, P., A. Van Loon, and W.W. Immerzeel. 2008. Quantifying the impact of model inaccuracy in climate change impact assessment studies using an agro-hydrological model. Hydrol. Earth Syst. Sci., $12,669-678$.

Elbers, J. A., Moors, E. J., \& Jacobs, C. M. J. 2010. Gemeten actuele verdamping voor twaalf locaties in Nederland. STOWA rapport 2010-36, Amersfoort.

Groenendijk, P., L.V. Renaud \& J. Roelsma. 2005. Prediction of nitrogen and phosphorus leaching to groundwater and surface waters. Process descriptions of the ANIMO 4.0 model. Alterra-rapport 983, Wageningen.

Groenendijk, P., M. Heinen, G. Klammler, J. Fank, H. Kupfersberger, V. Pisinaras, A. Gemitzi, S. PeñaHarod, A. García-Prats, M. Pulido-Velazquez, A. Perego, M. Acutis, and M. Trevisan. 2014. Performance assessment of nitrate leaching models for highly vulnerable soils used in low-input farming based on lysimeter data. Science of the Total Environment 499: 463-480.

Heinen, M., G. Bakker, J.H.M. Wösten. 2020. Waterretentie- en doorlatendheidskarakteristieken van boven- en ondergronden in Nederland: de Staringreeks. Update 2018. Report 2987, Wageningen Environmental Research, Wageningen, https://doi.org/10.18174/512761

Heinen, M., F. Brouwer, K. Teuling, D. Walvoort, 2021a. BOFEK 2020 - Bodemfysische schematisatie van Nederland. Update bodemfysische eenhedenkaart. Rapport xxxx, Wageningen Environmental Research.

Heinen, M., P.E. Dik, J.J.P. Cruijsen. 2021b. Aanpassing en toepassing SWAP gericht op bodem en hydrologische maatregelen. Deelrapport thema Bewuste Bodem in onderzoeksprogramma Lumbricus. Rapport xxxx, Wageningen Environmental Research.

Janssen, P.H.M., A.C. Petersen, J.P. van der Sluijs, J.S. Risbey and J.R. Ravetz. 2003. RIVM/MNP Guidance For Uncertainty Assessment And Communication. Quickscan Hints \& Actions List. RIVM, Bilthoven, ISBN 90-6960-105-2.

Jury, W.A. and K. Roth. 1990. Transfer functions and solute movement through soil. Theory and applications. Birkhäuser Verlag, Basel, Switserland.

Kroes, J.G and P.E. Rijtema. 1996. TRANSOL, a dynamic simulation model for transport and transformation of solutes in soil. Report 103, DLO Winand Staring Centre, Wageningen, the Netherlands. 
Kroes, J.G., J.C. van Dam, R.P. Bartholomeus, P. Groenendijk, M. Heinen, R.F.A. Hendriks, H.M. Mulder, I. Supit, and P.E.V. van Walsum. 2017. SWAP version 4. Theory description and user manual. Report 2780, Wageningen Environmental Research, Wageningen, the Netherlands.

Kroes, J., R. Bartholomeus, J. van Dam, M. Hack-ten Broeke, I. Supit, R. Hendriks, A. de Wit, F. van der Bolt, D. Walvoort, I. Hoving \& J. van Bakel. Waterwijzer Landbouw, fase 2. Modellering van het bodemwater-plantsysteem met het gekoppelde instrumentarium SWAP-WOFOST. Rapport 2015-16, STOWA, Amersfoort.

Kroes, J., Supit, I., Van Dam, J., Van Walsum, P., \& Mulder, M. (2018). Impact of capillary rise and recirculation on simulated crop yields. Hydrology and Earth System Sciences, (April), 1-31.

http://doi.org/10.5194/hess-2017-223

Massop, H.T.L., Jansen, P.C., Beest, J.G. te, Kemmers, R., \& Van Der Gaast, J.W. 2001. Monitoring De Wildenborch. Verslag over de periode oktober 1995 - december 2000. Alterra rapport 414, Wageningen. http://edepot.wur.nl/231044

Mualem, Y. 1976. A new model for predicting the hydraulic conductivity of unsaturated porous media. Water Resources Research 12: 513-522.

Mulder, H. M., Bakel, P. J. T. van, Vos, A. de, Straten, G. van, Heinen, M., \& Kroes, J. G., 2018. SWAPWOFOST toepassing op Zilt Proefbedrijf Texel. STOWA Rapport 2018-01, Amersfoort.

Pouwels, R., J. Mol-Dijkstra, W. Wamelink. 2018. Kwalitatieve modelanalyse van de MetaNatuurPlanner v2.0. WOt-interne notitie 204, Wettelijke Onderzoekstaken Natuur \& Milieu, Wageningen.

Renaud, L.V., J. Roelsma \& P. Groenendijk. 2005. ANIMO 4.0. User's guide of the ANIMO 4.0 nutrient leaching model. Alterra-rapport 224, Wageningen.

Schipper, P.N.M., M. Heinen, P. Jansen, L. Stuyt en P. Dik. Praktijkproef Regelbare Drainage proefbedrijf Rusthoeve 2010-2014. Eindverslag proef naar de effecten van regelbare en verdiept aangelegde drains op klei in Zeeland. Alterra-rapport 2639. Wageningen.

Srivastava, R. and T.C.J. Yeh. 1991. Analytical solutions for one-dimensional, transient infiltration towards the water table in homogeneous and layered soils. Water Resources Research 27: 753-762.

Stahn, P., S. Busch, T. Salzmann, B. Eichler-Löbermann, and K. Miegel. 2017. Combining global sensitivity analysis and multiobjective optimisation to estimate soil hydraulic properties and representations of various sole and mixed crops for the agrohydrological SWAP model. Environ Earth Sci: 76:367

Van Dam, J.C. and R.A. Feddes. 2000. Numerical simulation of infiltration, evaporation and shallow groundwater levels with the Richards equation. Journal of Hydrology 233: 72-85.

van Dam, J.C., Groenendijk, P., Hendriks, R.F.A., \& Kroes, J.G. 2008. Advances of Modeling Water Flow in Variably Saturated Soils with SWAP. Vadose Zone Journal, 7(2), 640-653.

http://doi.org/10.2136/vzj2007.0060

Vanderborght, J. and H. Vereecken. 2007. Review of Dispersivities for Transport Modeling in Soils. Vadose Zone Journal 6: 29-52.

Vanderborght, J., R. Kasteel, M. Herbst, M. Javaux, D. Thiéry, M. Vanclooster, C. Mouvet, and H. Vereecken. 2005. A set of analytical benchmarks to test numerical models of flow and transport in soils. Vadose Zone Journal 4: 206-221.

van der Hoeven, P.J.T. 2011. Lysimeters Castricum. Meetproject en datafiles. Alterra-rapport 2053-1, Wageningen. https://library.wur.nl/WebQuery/wurpubs/fulltext/175796 
Van Genuchten, M.Th. 1980. A closed-form equation for predicting the hydraulic conductivity of unsaturated soils. Soil Science Society of America Journal 44: 892-898.

van Walsum, P.E.V. en A.A. Veldhuizen. 2011. MetaSWAP_V7_2_0. Rapportage van activiteiten ten behoeve van certificering met Status A. WOt Werkdocumenten 276, Wettelijke Onderzoekstaken Natuur \& Milieu, Wageningen.

Walker, W.E., P. Harremoës, J. Rotmans, J.P. Van Der Sluijs, M.B.A. Van Asselt, P. Janssen And M.P. Krayer von Krauss. 2003. Defining Uncertainty. A Conceptual Basis for Uncertainty Management in Model-Based Decision Support. Integrated Assessment Vol. 4, No. 1, pp. 5-17.

Wanders, N., D. Karssenberg, M. Bierkens, R. Parinussa, R. de Jeu, J. van Dam, and Steven de Jong. 2011. Observation uncertainty of satellite soil moisture products determined with physically-based modeling. Remote Sensing of Environment 127: 341-356

Wösten, J.H.M., G.J. Veerman \& J. Stolte. 1994. Waterretentie- en doorlatendheidskarakteristieken van boven- en ondergronden in Nederland: de Staringreeks. Vernieuwde uitgave 1994. Staring Centrum Technisch Document 18, SC-DLO, Wageningen.

Wösten, J.H.M., G.J. Veerman, W.J.M. de Groot \& J. Stolte. 2001. Waterretentie- en doorlatendheidskarakteristieken van boven- en ondergronden in Nederland: de Staringreeks Vernieuwde uitgave 2001. Alterra rapport 153, Alterra, Wageningen. 